\title{
FATIGUE BEHAVIOUR OF FIBER REINFORCED BONE CEMENT
}

\author{
B. Kumar ${ }^{\dagger}$, F. W. Cooke ${ }^{\ddagger}$, E. A Friis ${ }^{*}$ and W. J. Horn ${ }^{\S}$ \\ ${ }^{\dagger}$ National Institute of Aviation Research, Wichita State University \\ Dept. Aerospace Engineering Wichita State University \\ ${ }^{\ddagger}$ Orthopaedic Research Institute Inc., Via-Christi Regional Medical Center - St. Francis Campus \\ Wichita, KS 67260 \\ Dept. Mechanical Engineering at University of Kansas, Lawrence, KS 66045
}

\begin{abstract}
The use of poly methyl methacrylate (PMMA) based bone cement as a grouting agent for the fixation of orthopaedic implants has been in practice for nearly fifty years. Fatigue fracture has been identified as the primary cause of cement failure. Implant loosening due to the failure of the cement is one of the major factors necessitating revision surgery. The need for a more fatigue resistant bone cement is well documented in literature, and one method of producing a more fatigue tolerant bone cement is to reinforce it with short fibers.

The fundamental objective of this work was to investigate the possible improvement of the fatigue characteristics of bone cement by incorporating two types of fiber reinforcement; short flexible fiber Polyethylene Terephalate (PET) fibers and stiff milled carbon fibers. The effects of the fiber reinforcement on the bone cement were determined experimentally. Since fatigue characteristics are known to have considerable scatter, the experimental data were analyzed statistically, the effect of the fiber reinforcement was also analyzed using a theoretical model coupled with extensive scanning electron microscopy of the fractured surfaces. The results of the research indicate that the fiber reinforcement improved the fatigue resistance of the bone cement. This could potentially lead to a more fatigue tolerant bone cement, which would delay implant loosening and the need for revision surgery.
\end{abstract}

\section{Introduction}

One of the most important aspects of prosthetic joint replacement is fixation of the artificial joint components to the bone. Essentially, all cases of the bone cement loosening can be traced to one of the following two causes: (a) septic loosening which occurs because of infection localized to the tissue around the implant, and (b) aseptic loosening which is due to mechanical failure of the prosthetic materials, the bone cement in particular. Although the mechanism of loosening is complex and influenced by a number of interdependent factors, it is generally recognized that some aspects of the mechanism are related to the mechanical and material properties of the bulk components and their interfaces in the fixation system. Ultimately, clinical failure manifests itself as unacceptable levels of pain or component loosening to such an extent that the prosthetic joint becomes non-functional. The stages of degeneration leading to clinical failure are dominated by the cement fracture, failure of the cement-implant interface and bone resorption around the implant secondary to release of particulate wear debris. Fatigue cracking of bone cement contributes either directly or indirectly to each of these processes. It has been suggested [1 through 12] that the primary underlying cause of aseptic failure is fracture of the bone cement. This fracture is most likely the result of fatigue loading, associated with locomotor activities.

The Initial fatigue studies of acrylic bone cement addressed the effects of variables such as cement type, storage and testing environment, mixing methods, and the effects of load frequency. The stress states reported in the literature range from axial loading in compression through compression-tension, tension-tension to rotating bending. The test frequency, varied from 1 to $30 \mathrm{~Hz}$ [8]. The higher frequencies can influence the results due to thermal softening of the PMMA bone cement which tends to increase the apparent fatigue life (cycles to failure) above that associated with the physiological frequencies of 1 to $2 \mathrm{~Hz}$. In addition test specimen conformation, which is the shape, size, void content, stress concentrations, surface conditions and residual stresses all have an influence on fatigue test results. A review of the literature on the fatigue testing of acrylic bone cement reveals the wide variety of testing modes, applied frequencies, specimen types and preparation, specimen sizes, stress ratios and test environment that have been used in the past. The effects of these parameters on fatigue resistance are summarized in Table 1. Because of the complexity of these multiple parametric dependencies it is difficult and often impossible to compare the results of various investigators. In an attempt to address theses difficulties an attempt was made in this study, to establish a standardized methodology and the resulting fatigue data were subjected to rigorous statistical analysis. 
Table 1: The effects of various parameters on the fatigue life of bone cement

\begin{tabular}{|c|c|}
\hline Test parameter & Effect on fatigue Life \\
\hline Stress Ratio $R$ & Not certain \\
\hline Specimen size & Increase in life with decrease in size \\
\hline Frequency & Increase in life with increase in frequency \\
\hline Void reduction & Increased Life \\
\hline Surface Machining & Decrease in life \\
\hline
\end{tabular}

In the literature, the most commonly used loading conditions involved a maximum stress of $15 \mathrm{MPa}$. To facilitate comparison of these studies most of the tests carried out in this investigation were conducted at a frequency of $2 \mathrm{~Hz}$ and a maximum stress of $15 \mathrm{MPa}$. The results of several investigators [1, 2, 5, 6, 7 and 8] conducted under these same conditions are presented in table 2.

Table 2: Comparison of fatigue cycles to failure of centrifuged and uncentrifuged bone cement specimens tested under identical test conditions: axial tension-compression at $2 \mathrm{~Hz}$ and initial stress of $15 \mathrm{MPa}$ and $50 \%$ probability of failure:

\begin{tabular}{|c|c|c|c|c|}
\hline Author & Cement & Uncentrifuged & Centrifuged & Increase \\
\hline Carter et al & Simplex P & 7,950 & & \\
\hline Burke et al. & Simplex P & 4,214 & 9,960 & 2.36 \\
\hline & Simplex P & 15,147 & 34,239 & 2.26 \\
& Zimmer Reg & 8790 & 24,231 & 2.76 \\
Davies et al. & Zimmer LVC & 2,575 & 8,233 & 3.19 \\
& Simplex P & 2,162 & 11,259 & 5.21 \\
& Zimmer Reg & 968 & 3,408 & 3.52 \\
& Zimmer LVC & 976 & 3,135 & 3.21 \\
\hline Harrigan et al. & Simplex P & 2,665 & 20,913 & 7.58 \\
\hline
\end{tabular}

\section{Objectives}

The majority of the efforts at improving the fatigue life of bone cement have focused on the reduction of porosity. Pilliar et al [9] were the earliest investigators to report an attempt to reinforce bone cement with short fibers to increase its fatigue tolerance. This concept has been carried forward in the present investigation by using fiber of different types, lengths, volume fractions and by surface treating the fibers in an attempt to increase the fiber/matrix interface strength.

Short fibers can be used in a brittle matrix, such as bone cement, to improve fatigue resistance because of their ability to dissipate the energy which is necessary for crack growth thereby increasing the toughness of the material. The basic mechanisms by which this energy dissipation occurs have not been explored in great detail but are known to include the following processes: fiber/matrix interface rupture, surface creation, post debond frictional work and fiber pullout. Therefore it is necessary to understand these mechanisms in order to maximize energy dissipation when a crack is propagating through a shot fiber reinforced brittle matrix like bone cement. To elucidate the operation of these mechanisms a multipronged approach was used. The key elements of this approach can be summarized as follows:

- A test program conducted to obtain fatigue data on fiber reinforced bone cement for a wide range of test conditions.

- Statistical analyses of the fatigue data.

- An analytical explanation for the observed results using energy principles.

- A fractographic study of the fracture surfaces of the fatigue specimens was performed to develop a deeper insight into the micro-mechanics of the fatigue of reinforced bone cement.

\section{Experimental Procedure}

The work of previous researchers [2, 3, 4, $5 \& 7$ ] clearly demonstrated the detrimental effect of porosity on the fatigue life of the bone cement. To determine the fatigue characteristics of bone cement without being unduly influenced by the inherent porosity of the material, the cement for this investigation was vacuum mixed and specimens with a pore size greater than $1 \mathrm{~mm}$ were discarded. To optimize the fiber reinforcement of the cement the effect of the following parameters were considered:

1. fiber types (stiff versus flexible)

2. fiber volume fraction

3. fiber surface treatments and

4. fiber lengths 
A complete S-N characterization of all the various specimen types incorporating each of these material variables would have been time consuming, expensive and generally impractical. Therefore, the comparison of all the specimen types was made by testing at a maximum stress of $15 \mathrm{MPa}$, since this is the most widely used stress level quoted in the literature on the subject.

The variability in the methods of fatigue testing as discussed earlier, can be grouped under two major headings specimen fabrication and testing methods. To reduce the variability in the fatigue test results, specimen preparation and the testing conditions were strictly controlled. Fatigue tests were performed on cylindrical specimens, with a gage diameter of 0.25 inches and a gage length of 0.75 inches. All of the specimens used in this study were prepared using Simplex $P^{\circledR}$ bone cement, and were mixed in a Stryker ${ }^{\circledR}$ vacuum mixing system using manufacturer's recommendations.

The fiber reinforced bone cement inserts were prepared with the following two fiber types (a) PET (polyethylene terephathalate) fibers and (b) milled carbon fibers. The PET "Type 100" Hoechst Celanese, Chatham, NJ had a vegetable base fatty acid ester surface coating. This coating was removed by washing the fibers with ethanol in a soxhlet extractor for six hours. Infrared spectroscopy of the fibers confirmed the removal of the fatty acid coating. These fibers are referred to as "scoured" PET fibers. The PET "Type 100" fibers had a diameter of $12 \mu \mathrm{m}$ and an elastic modulus, E, of $4.9 \mathrm{GPa}$. They were chopped to lengths of $1,1.5$, and $3.0 \mathrm{~mm}$ using a fixture designed for this purpose. Zoltek Corporation, St Louis, Missouri provided the milled carbon fibers, but no information about the fiber surface treatment was provided. The fibers were reported by the supplier to have an average length of $100 \mu \mathrm{m}$, a diameter of $7.2 \mu \mathrm{m}$ and an elastic modulus, E, of $228 \mathrm{GPa}$. The surface of some of the carbon fibers was treated to improve bonding between the fiber and the bone cement matrix. The carbon fibers were surface treated at the University of Missouri at Columbia by a plasma coating process. Basically the carbon fibers were exposed to TMS (Tri-methyl-silane) plasma for approximately 30 minutes.

During the cement preparation but prior to the addition of the liquid methyl methacrylate monomer the appropriate weight of fibers was mixed by gentle stirring of the fibers with the powder phase of the bone cement in a large container. The MMA monomer was then added and the cement mixed under vacuum to reduce porosity. The inserts (gage section) were molded in precision glass tubes with one end sealed. To do this the cement while in liquid state was transferred into the barrel of the injection gun. The gun was then fitted with a small diameter nozzle that would fit inside the glass tubes. The glass tube was placed over the nozzle and the tube was filled by gently pressurizing the cement in the gun. An O-ring coupled with the small diameter nozzle caused the cement to flow into the glass tube in a turbulent manner. As a result the fiber orientation was randomized as the cement filled the glass tube. The specimens were then placed in a curing tank of $0.9 \%$ saline solution maintained at $37^{\circ} \mathrm{C}$ for a minimum of 40 and a maximum of 120 days. Sometime during the curing stage the specimens were removed and $x$-rayed and specimens with voids greater than $1 \mathrm{~mm}$ were discarded. The acceptable specimens were returned to the curing chamber until aging was complete. The second stage of the specimen preparation was shoulder molding. Aged specimens were removed from the curing chamber and placed in a split mold. TMR epoxy 4045/3417 [PTM\&W Industries Inc] was used to mold the shoulders of the cylindrical ends. The specimens were removed from the mold and kept in a saline environment until they were tested.

\section{Testing conditions}

Tensile testing was conducted on a 5 kips MTS load frame, while the fatigue tests were conducted on six 0.5 kip MTS mini bionix load frames. The test fixtures used for the tensile tests were identical to those used for the fatigue tests. The tensile tests for all of the specimen types were conducted in air and under displacement control at a rate of $0.57 \mathrm{~mm} / \mathrm{minute}$ in order to achieve failure between one and two minutes. The fatigue testing was conducted on six MTS 0.5 kips capacity servo hydraulic test frames. The testing was done in an environment of $0.9 \%$ saline solution in an environmental chamber maintained at $37^{\circ} \mathrm{C}$. The tests were conducted under load control with sinusoidal tension-tension loading at $2 \mathrm{~Hz}$ and a stress ratio $(R)$ of 0.1 . All test data were recorded with the maximum stress being the identification stress. One of the major problems associated with uniaxial fatigue testing is ensuring adequate alignment so as to avoid bending and hence stress gradients in the specimen. To overcome these problems universal joints were designed using a chain link system. The complete S-N curve for five materials was generated with test data collected at $15 \mathrm{MPa}, 20 \mathrm{MPa}, 25 \mathrm{MPa}$, and $30 \mathrm{MPa}$. The endurance limit for all of the five material types was established at a million $\left(10^{6}\right)$ cycles using the two-point strategy [15].

\section{Results of the Experimental Study}

The detailed statistical evaluation of the fatigue data generated during this study can be found in [13]. Only the following aspects of the test results are presented here: (1) endurance limit evaluation and the (2) S-N curve generation using mean life data. The Endurance Limit of a material is defined as the maximum stress at which the material will last for a pre-specified number of cycles when subjected to cyclic loading. For most metals the endurance limit, or fatigue strength, is established as the largest stress for which the material can survive for ten million cycles of that stress at a frequency of 5 to 30 Hertz. For this investigation of bone cement the largest stress for which the bone cement can survive one million cycles at a frequency of 2 $\mathrm{Hz}$ was chosen as the required fatigue strength for bone cement. 
The endurance limit was evaluated using the Two-point Strategy. This procedure requires a schedule of testing to be continued until a nonzero and nonunity probabilities of failure are observed at two stress levels, $S_{1}$ and $S_{2}$. The median fatigue life is estimated by plotting the two proportions of failure (at the two stress levels) on probability paper and constructing a line through them. Alternately, the median fatigue life [15] can also be evaluated by the equation

$$
\hat{S}_{50}=S_{1}+\left(S_{2}-S_{1}\right)\left(-\hat{Y}_{1} /\left(-\hat{Y}_{1}+\hat{Y}_{2}\right)\right)
$$

where $S_{1}$ and $S_{2}$ are the two stress levels and $\hat{Y}_{1}$ and $\hat{Y}_{2}$ represent the normal deviates for an assumed normal distribution of failure for the two stress levels $S_{1}$ and $S_{2}$ and are obtained from the normal distribution tables.

The Two-point Strategy provided a procedure for calculating both the median fatigue strength, $\hat{\mathrm{S}}_{50}$, and the corresponding $95 \%$ confidence limits for median fatigue strength are $\hat{S}_{50}$, lo and $\hat{S}_{50}$, hi. The results of the calculations for the fatigue strength of all of the material types for which complete $\mathrm{S}-\mathrm{N}$ curves were generated, are presented in Table 2 . This table also contains the $95 \%$ confidence limits for the median fatigue strength for the five material types.

Table 3: Summary of the fatigue strength evaluation and $95 \%$ confidence limit for median fatigue strength

\begin{tabular}{|c|c|c|c|}
\hline Material Type & $\begin{array}{l}\hat{\mathrm{S}}_{50, \mathrm{lo}} \\
(\mathrm{MPa})\end{array}$ & $\begin{array}{c}\text { Fatigue strength } \\
\hat{S}_{50}(\mathrm{MPa})\end{array}$ & $\hat{S}_{50, \text { hi }}(\mathrm{MPa})$ \\
\hline Neat Bone Cement & 11.0 & 11.4 & 11.8 \\
\hline 1v/o scoured PET fiber reinforced bone cement & 10.8 & 11.8 & 12.8 \\
\hline $1 \mathrm{v} / \mathrm{o}$ as received carbon fibers reinforced bone cement & 10.8 & 12.6 & 14.4 \\
\hline 1v/o treated carbon fibers reinforced bone cement & 12.6 & 13.2 & 13.8 \\
\hline 2v/o as received carbon fibers reinforced bone cement & 13.1 & 13.6 & 14.1 \\
\hline
\end{tabular}

\section{S-N curves}

Statistical analyses of lifetime data by necessity require assumptions about the shape of the S-N curve. Various formulae for continuous curves representing the stress-endurance relationship have been suggested since the initial work by Wöhler. These formulae generally represent simple straight-line approximations in either Log-Linear or Log-Log coordinates. Specimens of the neat bone cement and the four reinforced bone cements were tested at four intermediate stress levels to determine the S-N plot over this intermediate range. These stress levels were $15 \mathrm{MPa}, 20 \mathrm{MPa}, 25 \mathrm{MPa}$, and $30 \mathrm{MPa}$. The fatigue strength evaluated at $10^{6}$ cycles, and the ultimate tensile strength provided the two end points. The fatigue data generated during this investigation have been plotted in the classical method of maximum stress (linear ordinate scale) versus cycles to failure (logarithmic abscissa scale). A summary of the fatigue data is given in Table 5.

The table contain the mean number of cycles to failure and the standard deviation at each of the intermediate stress levels, the upper and lower bounds of the $95 \%$ confidence limits of the number of cycles to failure are also provided for each stress level. The data were plotted in the classical S-N form as presented in figures 1 though 5 . Figure 6 shows the master plot were all the S-N curves are plotted together allowing for a direct comparison of the fatigue lives of the different reinforced bone cements with neat bone cement. The effects of the fiber reinforcement are clearly seen from the figure 6 . The fiber reinforcement of all types led to statistically significant increases in the fatigue life strength at maximum stresses of $15 \mathrm{MPa}$, which is the most widely reported stress level. The carbon $2 \mathrm{v} / 0$ reinforcement had the most substantial improvement. 
Table 5: Fatigue data for neat and composite bone cement

\begin{tabular}{|c|c|c|c|}
\hline $\begin{array}{l}\text { Maximum } \\
\text { stress }\end{array}$ & Specimen Type & $\begin{array}{c}\text { Cycles to failure } \\
\pm \text { Standard deviation }\end{array}$ & $\begin{array}{l}95 \% \text { upper and lower } \\
\text { confidence bounds }\end{array}$ \\
\hline \multirow{5}{*}{$30 \mathrm{MPa}$} & Neat & $693 \pm 353$ & 972 to 501 \\
\hline & PET & $514 \pm 424$ & 773 to 303 \\
\hline & $1 \mathrm{v} / \mathrm{o}$ as received carbon & $2,762 \pm 1,708$ & 4,746 to 1,942 \\
\hline & 1v/o treated carbon & $3,125 \pm 1,714$ & 5,217 to 1,911 \\
\hline & 2v/o carbon & $740 \pm 202$ & 740 to 472 \\
\hline \multirow{5}{*}{$25 \mathrm{MPa}$} & Neat & $3,300 \pm 1,457$ & 2,517 to 4,243 \\
\hline & PET & $7,927 \pm 4,125$ & 11,386 to 5,571 \\
\hline & $1 \mathrm{v} / \mathrm{o}$ as received carbon & $6,889 \pm 2,082$ & 8,268 to 5,803 \\
\hline & $1 \mathrm{v} / \mathrm{o}$ treated carbon & $14,217 \pm 5,679$ & 21,450 to 10,987 \\
\hline & 2v/o carbon & $9,137 \pm 4,364$ & 18,573 to 5,717 \\
\hline \multirow{5}{*}{$20 \mathrm{MPa}$} & Neat & $37,238 \pm 17,015$ & 27,003 to 51,769 \\
\hline & PET & $66,616 \pm 21,759$ & 87,631 to 53,883 \\
\hline & $1 \mathrm{v} / \mathrm{o}$ as received carbon & $79,031 \pm 15,538$ & 84,401 to 69,446 \\
\hline & 1v/o treated carbon & $118,301 \pm 49,698$ & 144,330 to 84,102 \\
\hline & 2v/o As Received carbon & $94,493 \pm 49,035$ & 134,727 to 68,890 \\
\hline \multirow{5}{*}{$15 \mathrm{MPa}$} & Neat & $233,161 \pm 53,815$ & 258,874 to 211,321 \\
\hline & PET & $293,528 \pm 79,435$ & 348,975 to 258,567 \\
\hline & $1 \mathrm{v} / \mathrm{o}$ as received carbon & $428,604 \pm 178,227$ & 543,351 to 345,937 \\
\hline & 1v/o treated carbon & $486,887 \pm 109,035$ & 548,993 to 437,926 \\
\hline & 2v/o As Received carbon & $717,072 \pm 223,840$ & 918,635 to 611,286 \\
\hline \multirow{5}{*}{$\begin{array}{c}\text { Ultimate } \\
\text { Tensile } \\
\text { Stress } \\
\text { [MPa] }\end{array}$} & Neat & $43.07 \pm 0.9 \mathrm{MPa}$ & 42.8 to $40.7 \mathrm{MPa}$ \\
\hline & PET & $45.2 \pm 1.13 \mathrm{MPa}$ & 43.9 to $42.5 \mathrm{MPa}$ \\
\hline & $1 \mathrm{v} / \mathrm{o}$ as received carbon & $45.2 \pm 1.13 \mathrm{MPa}$ & 46.1 to $44.3 \mathrm{MPa}$ \\
\hline & 1v/o treated carbon & $42.9 \pm 1.50 \mathrm{MPa}$ & 44.5 to $42.0 \mathrm{MPa}$ \\
\hline & 2v/o As Received carbon & $41.1 \pm 0.94 \mathrm{MPa}$ & 41.7 to $40.5 \mathrm{MPa}$ \\
\hline
\end{tabular}




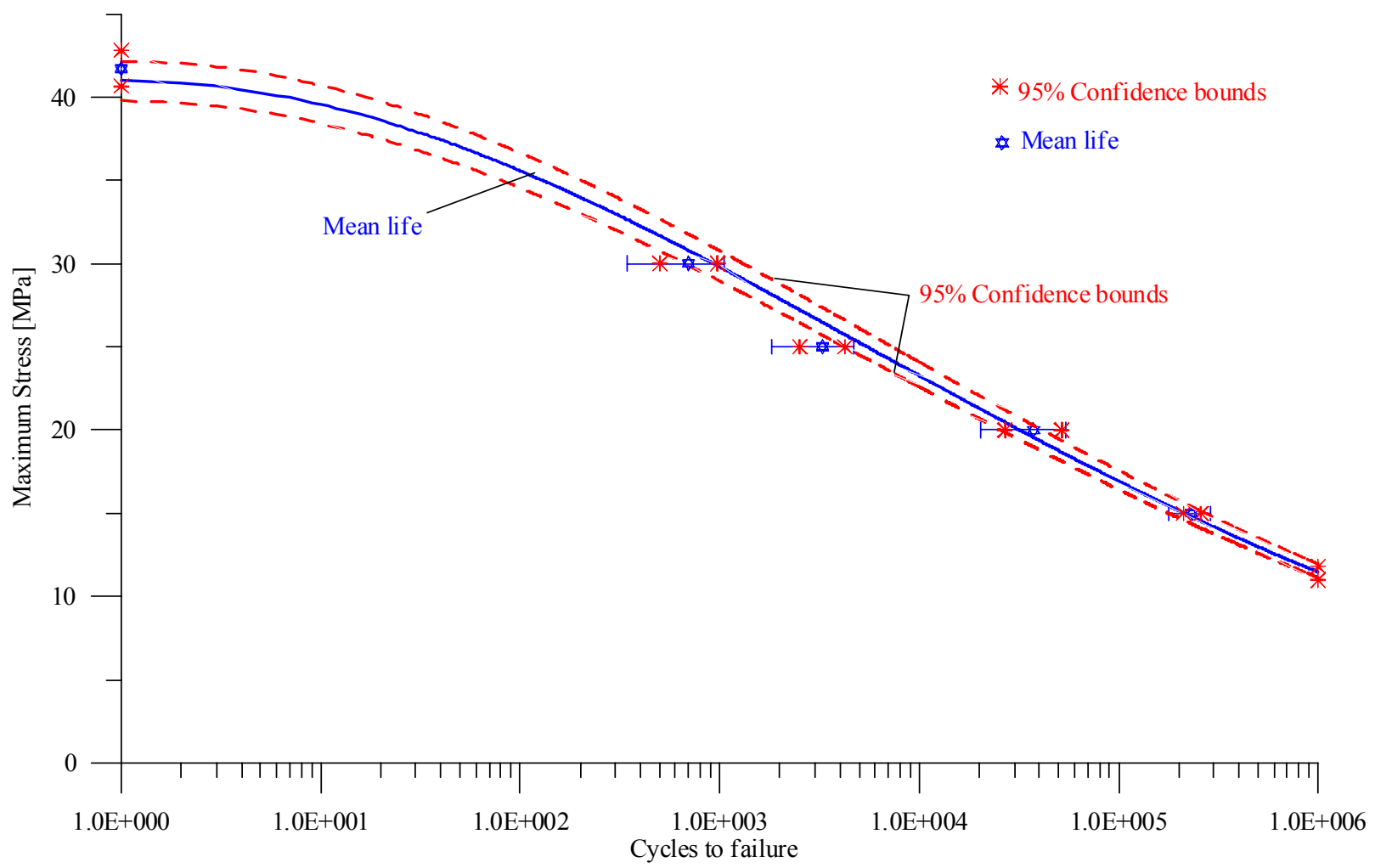

Figure 1. S-N curve of Neat Bone Cement

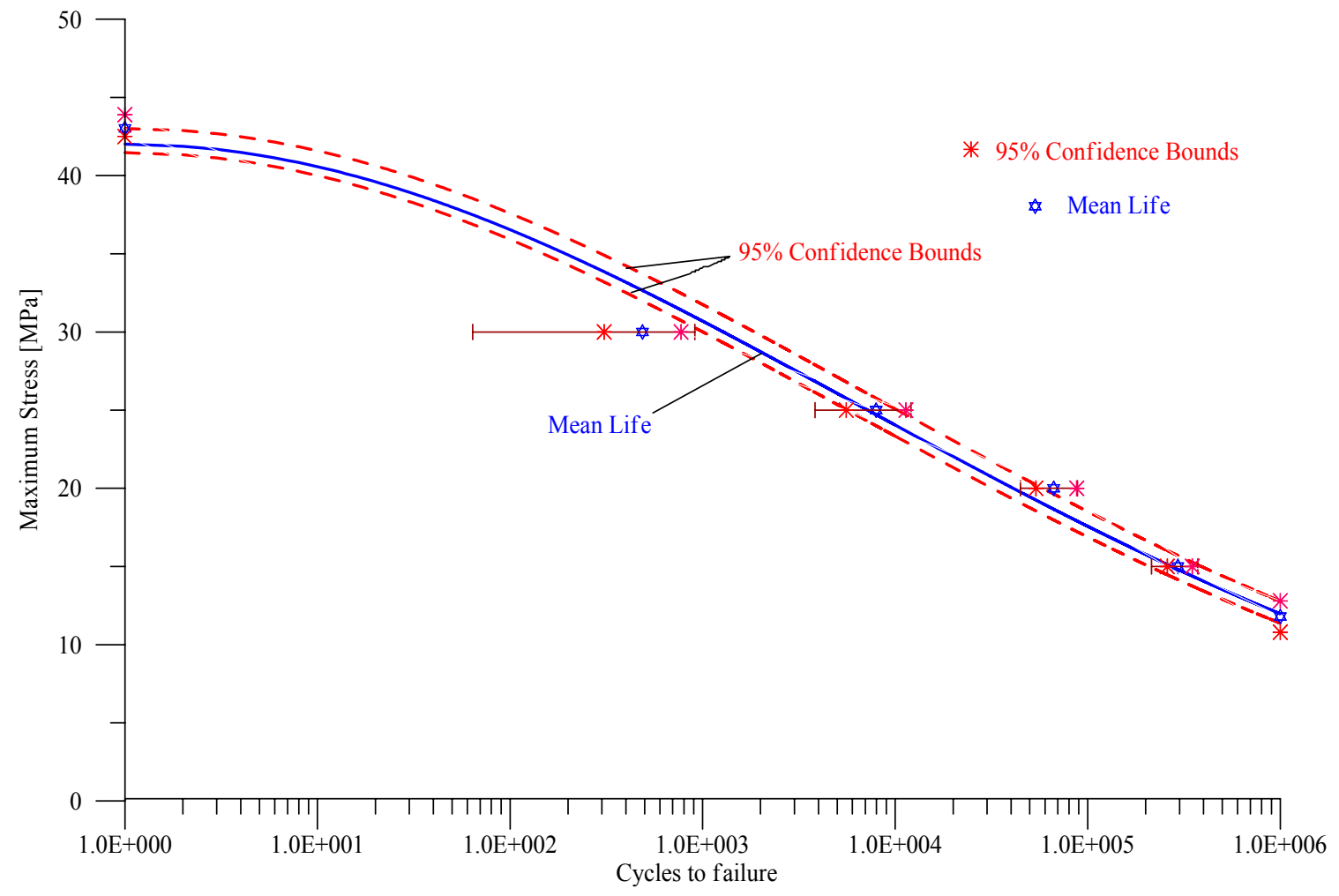

Figure 2. S-N curve of 1 v/o PET Reinforced Bone Cement 


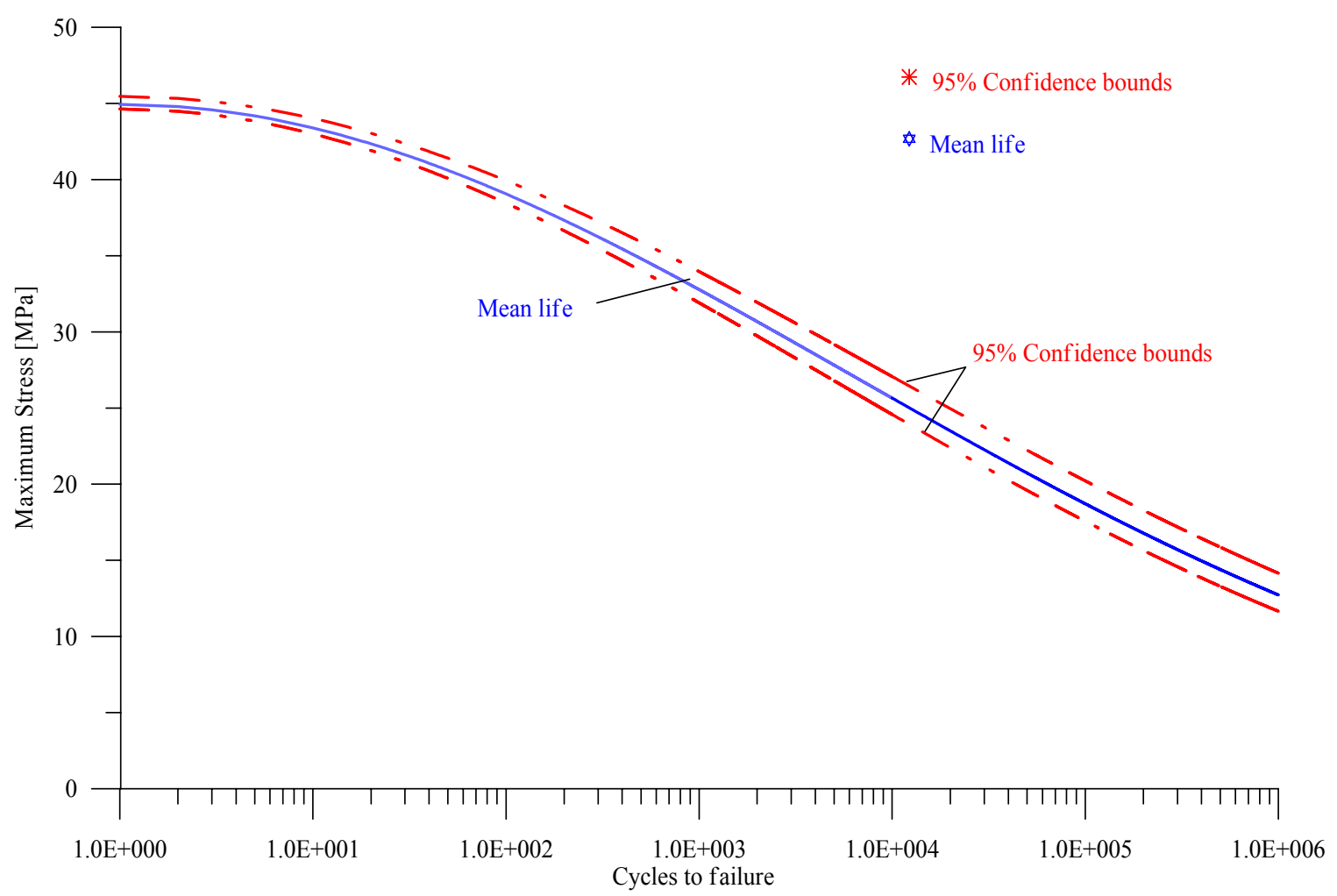

Figure 3. S-N curve of 1 v/o As Received - Carbon Fiber Reinforced Bone Cement

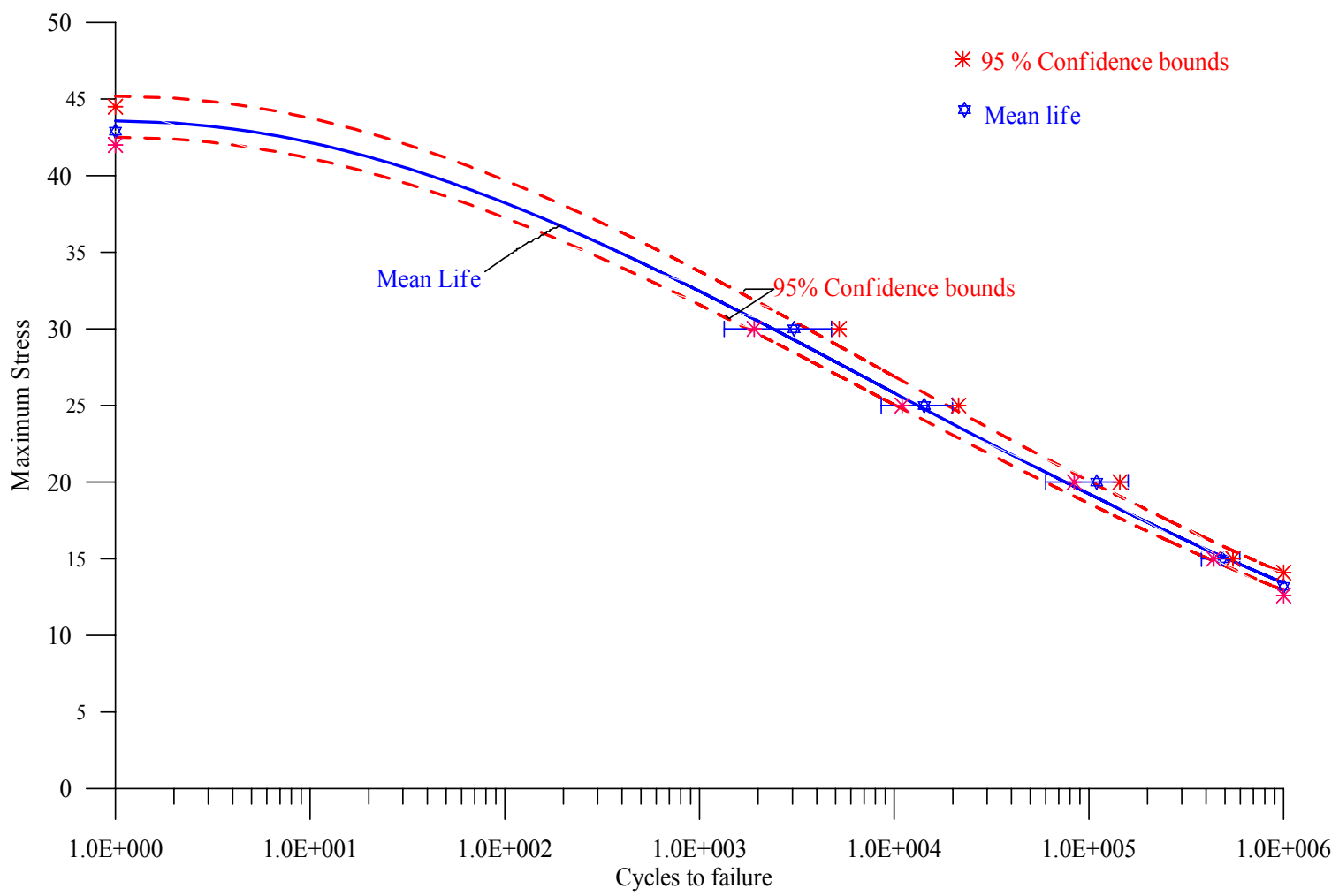

Figure 4. S-N curve of 1 v/o Treated - Carbon Fiber Reinforced Bone Cement 


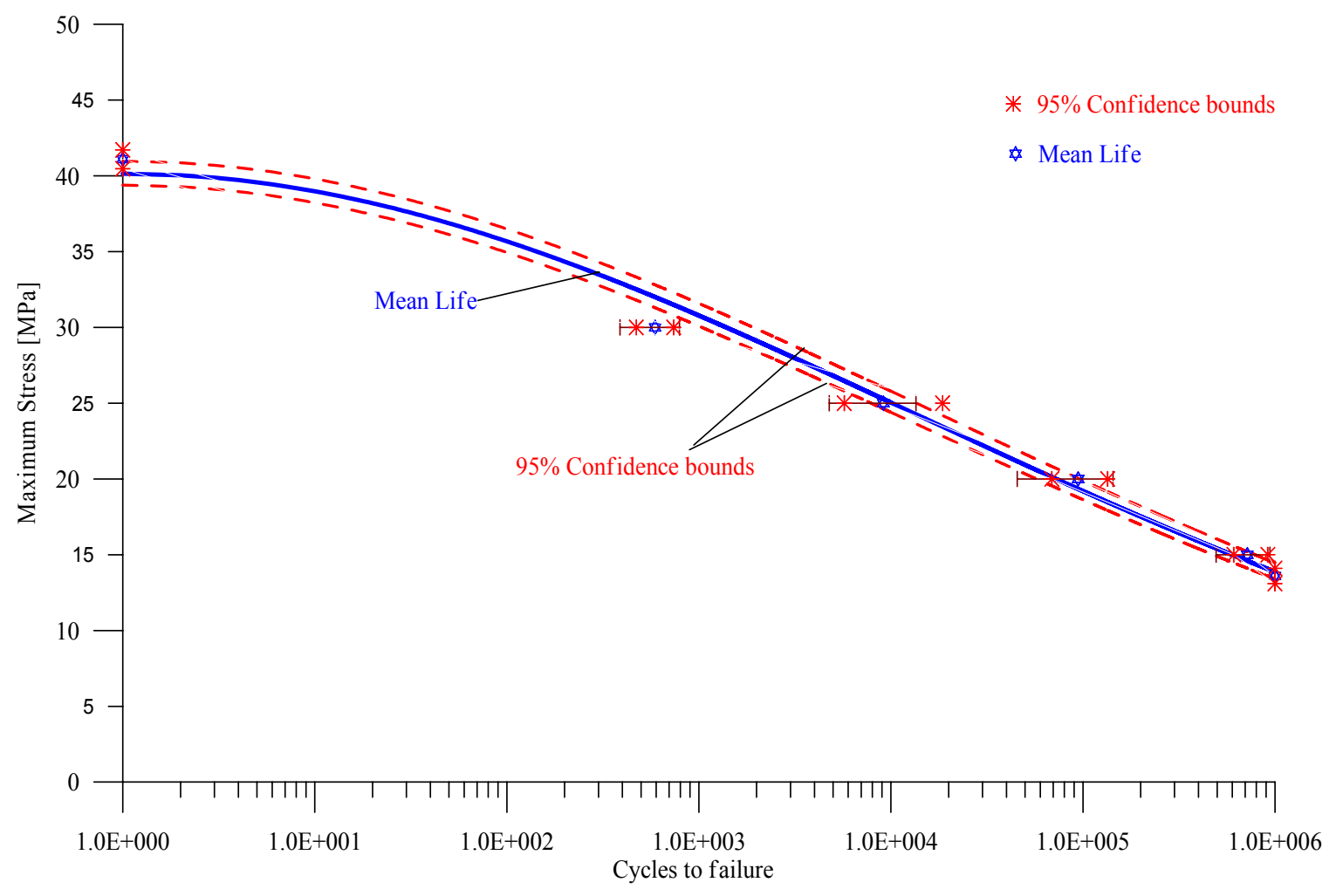

Figure 5. S-N curve of 2 v/o As Received - Carbon Fiber Reinforced Bone Cement

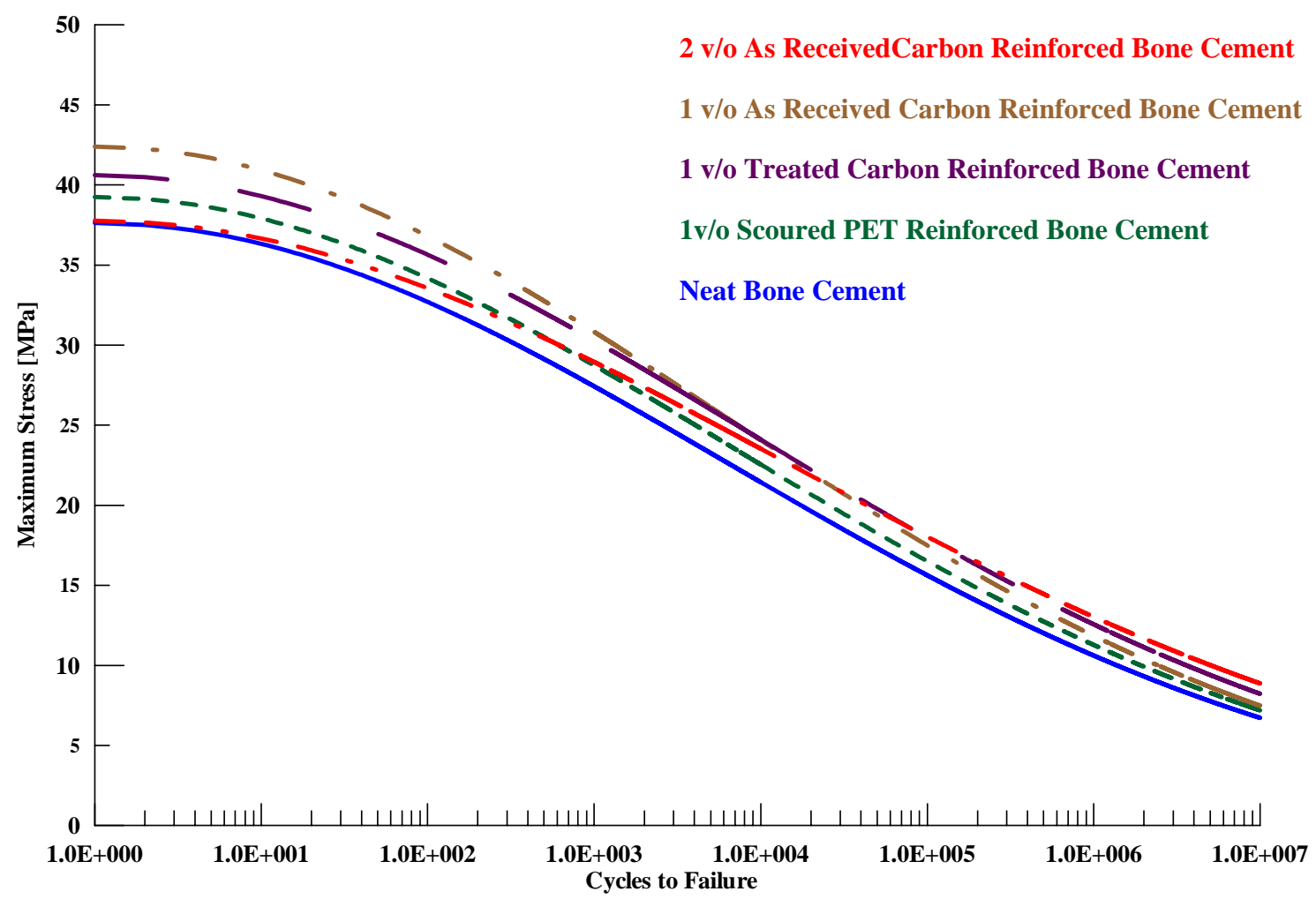

Figure 6. S-N Master plot of the 95\% Lower confidence bounds for neat and composite bone cement 


\section{Analytical Results}

An analytic method to explain the experimentally observed results was attempted using a basic approach to derive a comparative equation. This would explain the observed effects of fiber reinforcement on the fatigue life of bone cement. The second step of this approach was to derive the energy dissipation terms involved in the fracture of short fiber composites as a function of applied stresses. Since most the predictive models require an initial and final flaw size, but SEM evaluation of the fracture surfaces made it clear that the length of the crack could not be determined, though it was possible to determine the area associated with fatigue damage. Therefore the approach followed was to predict the fatigue life of the composite bone cement as compared to that of the neat bone cement fatigue life with no assumptions regarding initial damage. A relationship between the fatigue life of neat bone cement and composite bone cement was established using this approach.

\section{Fiber reinforcement}

Short fibers used as reinforcement in brittle matrix materials, like bone cement, are able to dissipate some of the energy necessary for crack growth [16, 17, and 18]. This dissipation of the available energy leads to a toughening of the material. The toughening mechanism is dependent on numerous factors the most important of which are the arrangement of fibers in the matrix, fiber length, fiber elastic modulus, fiber volume fraction, and the energy dissipation processes involving the interaction of the crack front with the fiber reinforcement.

Overall the effectiveness of the fiber reinforcement depends on the following:

1. Fiber orientation

2. Effect of fiber spacing

3. Effect of fiber-fiber interaction

The effect of fibers on the propagating crack depends on what proportion of fibers are oriented perpendicular to the advancing crack front and what proportions are oriented otherwise. Fiber orientation was determined by measuring the ratio of the major and minor axes of the resulting ellipses for the fibers in the polished cross section. The polished surfaces of the cross section of fifteen specimens were examined with an optical microscope to determine the average angle of fiber orientation. The specimens were sectioned transversely at three locations along the length to determine if there was any variation of the fiber angle along the length of the specimens. The average angle of fiber orientation measured from the axis through the centroid of each cross section of the three composite bone cements was:

(1) $\quad 17.4$ degrees for the one percent by volume PET specimens

(2) $\quad 38.1$ degrees for the one percent by volume carbon specimens and

(3) 37.8 degrees for the two percent by volume carbon specimens.

Mathematical modeling of crack propagation in a material with randomly oriented discontinuous fibers can be extremely complex. The model developed as part of this investigation assumed that an appropriate portion of the fibers were oriented normal to the advancing crack and that the remainder provided no reinforcement. An effective volume fraction of the fibers was sought that would account for the loss of fibers due to this orientation effect. The effective volume fractions of the fibers in the composite specimens were computed by the following equation [16 \& 17]:

$$
V_{f}^{\prime}=V_{f} \cos ^{2} \alpha
$$

where $\alpha$ is the average angle of orientation of the collection of fibers with the axis of the specimen. The stresses that arise in the fibers depend on the arrangement of the fibers in the matrix and for this analytical model the fibers were assumed to be distributed evenly throughout the volume of the specimen. The fibers were assumed to be separated by a distance $2 \mathrm{R}_{\mathrm{v}} \mathrm{where}$ the expression to determine $R_{v}$ is given by [18]:

$$
R_{v}=\sqrt{\frac{2 \pi}{v_{f}^{\prime}}} \frac{r}{(3)^{1 / 4}}
$$

where $v_{f}^{\prime}$ is the effective volume fraction of fibers and $r$ is the radius of the fibers.

Hence the two assumptions with regard to the arrangement of the fibers within the bone cement are:

1. The actual fiber orientation present in the specimen could be adequately represented, for the purpose of this analysis, by an appropriately reduced volume fraction of fibers all of which are oriented parallel to the specimen axis

2. The parallel fibers are distributed evenly throughout the specimen separated by a mean distance $2 R_{\mathrm{v}}$. The values for the mean separation distances were $0.25 \mathrm{~mm}$ for the PET, $0.176 \mathrm{~mm}$ and $0.126 \mathrm{~mm}$ for the one and two percent by volume carbon fiber reinforced cement.

The analysis of the added fibers contribution to the overall toughness of the composite, depends on the assumption that propagating cracks interact with the individual fiber and fiber-matrix interface in a manner that is independent of how the cracks interact with adjacent fibers [19]. If some of the fibers are so close together that these interactions are not entirely independent, i.e. the fibers are clumped to some degree, and this will reduce their reinforcement effectiveness. This reduced 
effectiveness can be treated as if it were an additional decrease in the effective volume fraction of the fibers in the composite. In order to account for the less than perfect mixing of fiber and bone cement, the number of fibers that were touching other fibers was counted for all the specimens that were used for the angle measurements discussed earlier. Therefore for every material type fifteen cross-sections were examined and the average number of fibers in contact with other fibers was determined. The number of fibers in a cross section of the specimen can be calculated using the relationship [20]

$$
\mathrm{N}=\frac{\mathrm{V}_{\mathrm{F}} \mathrm{A}_{\mathrm{C}}}{\pi \mathrm{r}^{2}}
$$

where $\mathrm{N}$ is the total number of fibers, $V_{F}$ is the fiber volume fraction, $A_{c}$ is the area of the specimen cross section, and $r$ is the radius of the fiber. The number of such fibers was subtracted from the total number of fibers $\mathrm{N}$, in the cross section and the reduced volume fraction was calculated for each of the three reinforced bone cements. Note that the stress concentration that occurs due to the void formation around each fiber was not accounted for in this model. The reduced effective volume fraction after accounting for both fiber orientation and fiber clumping was determined by multiplying the factors. The resulting effective fiber volume fractions considering all the three effects are given in Table 6.

\section{Energy dissipation due to fiber reinforcement}

The following assumptions were made to derive all of the terms that contribute to the work of fracture of the fiber reinforced bone cement composites:

(1) the fibers are of equal length and diameter

(2) the fibers are distributed uniformly throughout the cross section and

(3) the fibers are parallel to the direction of applied loading.

In order to account for these assumptions, the fiber volume fraction was reduced as described in the previous sections. When a crack moves through a matrix containing fibers, the following mechanisms are expected to operate: (a) fiber-bone cement interface failure (b) post debonding frictional work and (c) fiber pullout.

\section{Work done during surface creation in composite bone cement}

The following three surfaces are formed in composite bone cement during fracture: (a) fiber cross-section surfaces after fracture, (b) bone cement cross-sectional surfaces after fracture, and (c) the cylindrical surfaces created between the fiber and bone cement [21]. Photomicrographs of the fractured surfaces revealed that fiber pullout and debonding were the mechanisms present at failure and that fiber damage was rarely observed. Also no evidence of fiber fracture was observed. Consequently, in this analysis it was assumed that fiber fracture did not occur.

The work done in creating this surface may be formulated from basic work considerations [19]. The total energy associated with the surface creation of the composite bone cement can be written as

$$
W_{\text {SComp }}=\left(1-V_{f}\right) W_{\text {neat }}+\frac{V_{f} L Y_{\text {if }}}{r}
$$

$\mathrm{W}_{\text {neat }}$ was determined from the apparent fracture toughness of the neat cement to be $786 \mathrm{~N} / \mathrm{m}$. The interfacial fracture toughness between the fiber and the bone cement was needed, but in its absence the toughness of the bone cement was substituted for the interfacial fracture toughness. Obviously, by accepting this approximation only an upper bound for the work to generate debonded surfaces can be obtained. From the SEM observation of the composite specimens the bone cement matrix was observed to have adhered to the carbon fibers after the fracture in some of the photomicrographs, but no matrix was seen clinging to the PET fiber surface in any of the photomicrographs. Also the interface toughness for the PET-bone cement was assumed to be zero because the cylindrical surfaces in the PET reinforced specimens had no features to them. The interfacial toughness value used for the carbon fiber reinforced material was the toughness value for neat cement. The energy required for the surface creation during crack propagation within the $1 \mathrm{v} / \mathrm{o}$ and $2 \mathrm{v} / \mathrm{o}$ carbon fiber and PET reinforced bone cement in terms of the energy required for neat bone cement are:

1. $\Delta \mathrm{G}_{\mathrm{C} \text {-comp }}=1.2 \Delta \mathrm{G}_{\text {neat }}$ for the $1 \mathrm{v} / \mathrm{o}$ carbon reinforced cement

2. $\Delta \mathrm{G}_{\mathrm{C} \text {-composite }}=1.4 \Delta \mathrm{G}_{\text {neat }}$ for the $2 \mathrm{v} / \mathrm{o}$ carbon reinforced cement, and

3. $\Delta G_{\text {PET-comp }}=\Delta G_{\text {neat }}$ for the PET reinforced cement.

\section{Frictional work after debond}

After the fiber-cement interface is broken there is a differential displacement between the bone cement and the fiber, the work done during this displacement is the frictional work after debond. The energy dissipated as a consequence is equal to the frictional force times the differential displacement between the fiber and the bone cement. Kelly suggested [18] that an approximate value of this displacement may be taken to be the product of the debonded length of the fiber $L_{d}$, times the differential strain $\Delta \varepsilon$. Therefore by approximating the differential strain $\Delta \varepsilon$ to be 0.01 [21], the maximum value for the work associated with post debonding occurs when the shear stress can be equated to the fracture stress of the fiber, thus the maximum value of $W_{d f}$ can be written as

$$
\mathrm{W}_{\mathrm{dfmax}} \approx \frac{\sigma_{\mathrm{f}, \mathrm{u}} \mathrm{V}_{\mathrm{f}} \mathrm{L}}{100}
$$


The work associated with the frictional debond of the fiber in the three cases of composite bone cement investigated is also presented in Table 6. Since it was previously assumed that there was no interfacial bonding between the PET fiber and the bone cement, the work of frictional debond was assumed to be zero.

\section{The fiber pullout mechanism}

Kelly and Marston et al [18 \& 22] proposed a model for the mechanism of fiber pullout. Their mechanism centers around computing the work done against sliding friction in extracting fibers from the bone cement matrix after the propagating crack has passed. To consider the energy required to pull out one fiber from the bone cement, the resisting frictional stress was assumed to be $\mathrm{T}$, the fiber-cement stress. The maximum value of $\mathrm{T}$ is limited by the shear strength of the bone cement. Frictional stress was assumed to be constant over the length of the fiber that is pulled out. Considering an element of length $\delta z$, which is a distance $z$ from the fracture surface of the broken bone cement. The work done in extracting the element is equal to $2 \pi r r \delta z$. The pullout length will range from 0 to $0.5 \mathrm{~L}$. Where $L$ is the length of the fiber, $r$ is the radius of the fiber and $\sigma_{f, u}$ is the ultimate tensile strength of the fiber. Thus the maximum value for the work of pullout can be written as

$$
\mathrm{W}_{\mathrm{Pmax}}=\frac{\mathrm{V}_{\mathrm{f}} \sigma_{\mathrm{f}, \mathrm{u}} \mathrm{L}}{12}
$$

The work associated with fiber pullout for the three cases of composite bone cement investigated along with the effective fiber volume fraction and maximum work of frictional debond is presented in Table 6.

Table 6: Usable effective fiber volume fraction, work of frictional debond and work of pullout and its maximum value

\begin{tabular}{|c|c|c|c|c|c|c|}
\hline Material type & $\begin{array}{l}\text { Fiber } \\
\text { volume } \\
\text { added }\end{array}$ & $\begin{array}{c}\text { Effective } \\
\text { fiber volume } \\
\text { percent }\end{array}$ & $\begin{array}{l}\text { Work of frictional } \\
\text { debond } W_{d f}\end{array}$ & $\begin{array}{c}\text { Maximum work } \\
\text { of frictional } \\
\text { debond } \\
\mathrm{W}_{\mathrm{dfmax}}[\mathrm{N} / \mathrm{m}]\end{array}$ & $\begin{array}{l}\text { Work of pullout } \\
\qquad \mathrm{W}_{\mathrm{P}}[\mathrm{N} / \mathrm{m}]\end{array}$ & $\begin{array}{l}\text { Maximum } \\
\text { work of pullout } \\
W_{P \max }[\mathrm{N} / \mathrm{m}]\end{array}$ \\
\hline $\begin{array}{l}1 \mathrm{v} / \mathrm{o} \text { PET } \\
\text { composite }\end{array}$ & 1 & 0.86 & $2.209(10)^{-6} \sigma_{\text {applied }}$ & 0 & $\begin{array}{c}1.841(10)^{-} \\
{ }^{5} \sigma_{\text {applied }}\end{array}$ & 265 \\
\hline $\begin{array}{l}1 \text { v/o carbon } \\
\text { composite }\end{array}$ & 1 & 0.59 & $1.111(10)^{-7} \sigma_{\text {applied }}$ & 22 & $\begin{array}{l}9.25(10)^{-} \\
{ }^{9} \sigma_{\text {applied }}\end{array}$ & 187 \\
\hline $\begin{array}{l}2 \text { v/o carbon } \\
\text { composite }\end{array}$ & 2 & 1.17 & $2.49(10)^{-7} \sigma_{\text {applied }}$ & 45 & $\begin{array}{c}2.075(10)^{-} \\
{ }^{6} \sigma_{\text {applied }}\end{array}$ & 371 \\
\hline
\end{tabular}

\section{Analytical and experimental values of work of fracture}

The terms of pullout frictional debond and interfacial failure were evaluated for their maximum value and compared to the experimentally available fracture toughness values to verify whether the terms of fracture are accurate in describing the energy dissipation process. The total work of fracture for the neat bone cement can be evaluated as $\mathrm{K}_{\mathrm{IC}}{ }^{2} / \mathrm{E}$, where $\mathrm{K}_{\mathrm{IC}}$ is the fracture toughness and $E$ the elastic modulus of the material. The fracture toughness values for the various composite bone cements were experimentally determined in a prior study [23 \& 24], and the value for neat bone cement is $1.51 \mathrm{MPa}(\mathrm{m})^{1 / 2}$, for $1 \mathrm{v} / \mathrm{o}$ as received carbon it is $1.95 \mathrm{MPa}(\mathrm{m})^{1 / 2}$, for $2 \mathrm{v} / \mathrm{o}$ as received carbon it is $2.27 \mathrm{MPa}(\mathrm{m})^{1 / 2}$, and for scoured $1 \mathrm{v} / \mathrm{o} \mathrm{PET}(\mathrm{mm})$ it is $1.86 \mathrm{MPa}(\mathrm{m})^{1 / 2}$. The work required for surface creation within the neat bone cement specimen of this investigation was equated to the work of fracture of neat bone cement. This was experimentally determined to be $786 \mathrm{~N} / \mathrm{m}$. The work of fracture of the fiber reinforced bone cement can be thought of as consisting of two parts, namely the neat and the composite parts:

$$
W_{F}=W_{N}+W_{C}
$$

The total work associated with the fracture of neat bone cement is $W_{F}$. The composite part of the work of fracture is that associated with the fracture of the fiber reinforcement is given by the following equation:

$$
W_{F}=W_{N}+\frac{T V_{f} L^{2}}{12 r}+\frac{T V_{f} L^{2}}{100 r}+\frac{V_{f} L Y_{i f}}{r}
$$

Table 7 contains the computed values of each of the terms involved in the fracture of each of the composite bone cements studied along with the experimentally determined work of fracture for the neat bone cement, and a comparison of the experimentally determined values of the work of fracture with the analytically determined values for the different material types.

In the analytical model the work of fracture associated with fiber pullout and frictional debond are both dependent on the square of the fiber length. The PET fiber is an order of magnitude longer than the carbon fibers. Consequently the analysis predicted that the PET reinforced bone cement should have almost as good a reinforcing effect as the carbon reinforced cement as seen in Table 7. The measured effect of fiber length on fracture toughness was not found to be nearly as great as the analytical approach would predict [13], showing only an increase in the toughness from $1083 \mathrm{~N} / \mathrm{m}$ to $2556 \mathrm{~N} / \mathrm{m}$ as the fiber length increased from $1 \mathrm{~mm}$ to $6 \mathrm{~mm}$ for the PET reinforced fibers. There could be several explanations for this difference in 
theory and reality. Primarily the incorporation of the fibers in cement becomes difficult as the length of the fibers increases. Hence the expected benefits associated with reinforcement from a longer fiber may not occur. Also, as the fibers do not incorporate completely, they tend to create voids and clumps of unincorporated fiber, thereby weakening the cement. Further the reinforcing effect of the fibers decreases when the length of the fiber exceeds the critical length of the fiber. Consideration on the calculated results and the experimental findings would suggest the critical length of the PET fiber appears to be between 1 and $1.5 \mathrm{~mm}$. The effect of the fiber modulus and the fact that carbon fiber incorporated better in the bone cement when compared to PET fibers were also probable reasons that the toughening effect was higher for the carbon fiber than the PET fiber.

Table 7: The results of the work of fracture in composite bone cement reinforced with different types of fibers

\begin{tabular}{|c|c|c|c|c|c|c|c|}
\hline $\begin{array}{c}\text { Material } \\
\text { type }\end{array}$ & $\begin{array}{c}\text { Neat } \\
\text { cement } \\
\mathrm{W}_{\text {surface }}\end{array}$ & $\begin{array}{c}\mathrm{W}_{\mathrm{Pmax}} \\
\mathrm{N} / \mathrm{m}\end{array}$ & $\begin{array}{c}\text { Composite } \\
\mathrm{W}_{\text {dfmax }} \\
\mathrm{N} / \mathrm{m}\end{array}$ & $\begin{array}{c}\mathrm{W}_{\mathrm{IF}} \\
\mathrm{N} / \mathrm{m}\end{array}$ & Experimental & Calculated & $\begin{array}{c}\text { Error } \\
(\%)\end{array}$ \\
\hline Neat & 786 & $-\mathrm{NA}-$ & $-\mathrm{NA}-$ & $-\mathrm{NA}-$ & & & \\
\hline PET & 786 & 265 & 0 & 0 & 1193 & 1051 & 12 \\
\hline 1 v/o carbon & 786 & 197 & 24 & 129 & 1311 & 1136 & 13 \\
\hline 2v/o carbon & 786 & 371 & 45 & 256 & 1777 & 1458 & 18 \\
\hline
\end{tabular}

\section{Relationship of energy dissipation to fatigue life}

Experimental data with specimens containing pre-existing flaws are required to determine the fatigue crack propagation rate necessary for the classical fracture mechanics approach for obtaining a relationship relating fatigue life to stress, the approach shown above does not overcome this shortcoming, therefore a procedure that does not depend on the initial crack length was pursued.

The stress intensity factor is related to the applied stress by

$$
\mathrm{K}=\sigma(\pi \mathrm{a})^{1 / 2}
$$

Furthermore, the stress intensity factor, Young's Modulus and strain energy release rate are related by the expression

$$
\frac{\mathrm{K}^{2}}{\mathrm{E}}=\mathrm{G}
$$

The strain energy release rate is related to the work of fracture by the expression

$$
\mathrm{G}=2 \mathrm{\gamma}_{\mathrm{F}}
$$

Combining Equations 10,11 and 12 at the point of fracture leads to

$$
\frac{\sigma_{F}^{2} a}{2 E}=\frac{Y_{F}}{\pi}
$$

where $\sigma_{F}$ is the stress at fracture and $\frac{Y_{F}}{\pi}$ is a constant for a given material type. The fact that $\frac{\sigma_{F}^{2} a}{2 E}$ is a constant for a given material leads to the expression

$$
\frac{a_{1}}{a_{2}}=\left(\frac{\sigma_{F 2}}{\sigma_{F 1}}\right)^{2}
$$

Elastic strain energy is applicable to the last cycle of fatigue, let the energy associated with the accumulation of damage prior to the final fracture of the material be called the plastic energy. Generally when considering metals the zone of deformed material ahead of the crack, called the plastic zone, has a radius of $r_{p}$ that is proportional to the size of the crack and the stress intensity factor. The radius of the plastic zone can be expressed as a function of $K_{I}$ and the yield stress of the material, by the following relationship:

$$
r_{p}=\frac{1}{6 \pi}\left(\frac{K_{l}}{\sigma_{y s}}\right)^{2}
$$

In terms of applied stress, the radius of the plastic zone can be written as

$$
r_{P}=\frac{1}{6 \pi} \frac{\sigma^{2} a}{\sigma_{y s}^{2}}
$$

Even though a plastic zone of constant thickness, $t$, ahead of the crack tip is generally assumed, it may not necessarily exist in reality. However, for a brittle material, like bone cement, the condition of plain strain can be assumed since the ductility of the 
material is very small. Furthermore, the fracture toughness tests were conducted under plain strain conditions and these results were used in determining the work of fracture. Thus the plastic zone volume is assumed to be of uniform thickness. With this assumption of contant thickness of the plastic zone, the volume of the plastic zone becomes

$$
\text { Volume }=\left(\pi r_{\mathrm{p}}^{2}\right) t
$$

But the radius of the plastic zone is proportional to the crack length, $a$, that is

$$
\begin{aligned}
& r_{P} \propto a \\
& \text { Volume } \propto(a)^{2}
\end{aligned}
$$

and the work associated with fracture is also proportional to the square of the crack length

$$
\frac{W_{\mathrm{P} 1}}{W_{\mathrm{P} 2}}=\frac{a_{1}^{2}}{a_{2}^{2}}
$$

The crack length is proportional to the square of the stresses. Thus the stress levels associated with the two different crack lengths are related by Equation 14 and the work of fracture can be related to the stress by

$$
\frac{W_{\mathrm{P} 1}}{\mathrm{~W}_{\mathrm{P} 2}}=\left(\frac{\sigma_{\mathrm{F} 2}}{\sigma_{\mathrm{F} 1}}\right)^{4}
$$

Denoting the cyclic stress amplitude by $\sigma_{\mathrm{a}}, \mathrm{W}_{\mathrm{P}}$ is the total plastic work, $\sigma_{\mathrm{F}}$ is the true fracture stress, and $\mathrm{W}_{\mathrm{F}}$ is the work of fracture, the previous equation can be rewritten as

$$
\frac{W_{F}}{W_{P}}=\left[\frac{\sigma_{a}}{\sigma_{f}}\right]^{4}
$$

The work of fracture per unit area can be written as,

$$
\mathrm{W}_{\mathrm{F}}=\frac{\mathrm{K}_{\mathrm{IC}}^{2}}{\mathrm{E}}
$$

where the $E$ is the elastic modulus of the bone cement (note that the elastic modulus of the composite bone cement was essentially the same as that of the neat bone cement) and $\mathrm{K}_{\mathrm{IC}}$ is the fracture toughness of the material. The fracture stress of axially loaded specimens was determined using the relationship

$$
\sigma_{F}=\frac{P_{\max }}{A-A_{F}}
$$

where $P_{\max }$ is the maximum axial load at a given stress range, $A$ is the total cross-sectional area and $A_{F}$ is the area of fatigue. Therefore, substituting Equations 21 and 24 into Equation 23 leads to an expression for the plastic work per unit area that can be written in the following form:

$$
W_{P}=\left[\frac{P_{\max }}{\sigma_{a}\left(A-A_{F}\right)}\right]^{4} W_{F}
$$

The area of fatigue of each of the material types was determined for one specimen of the material, (at a stress level of $25 \mathrm{MPa}$ the high stress-low cycle range), and one specimen each from the low stress-high cycle range of 12 to $14 \mathrm{MPa}$ range. The areas of fatigue along with the experimentally determined cycles to failure are given in Table 8.

The following fracture toughness values were obtained from references 23 and 24 and the plastic work for each of the four material types was calculated using Equation 25.

The life of neat bone cement multiplied by the ratio of the plastic work of the neat cement and reinforced composite cements determined the predicted life of the reinforced bone cement specimen life. Hence the predicted life is given by

$$
\mathrm{N}_{\mathrm{c}}=\mathrm{N}_{\mathrm{N}} \frac{\mathrm{W}_{\mathrm{Pc}}}{\mathrm{W}_{\mathrm{Pn}}}
$$

where the $\mathrm{N}_{\mathrm{N}}$ is the life of the neat bone cement specimen at a given stress level, and $\mathrm{W}_{\mathrm{Pc}}$ and $\mathrm{W}_{\mathrm{Pn}}$ are the unrecoverable plastic work of the composite bone cement and the neat bone cement material respectively. The predicted life is compared to the measured mean life for both the high stress-low cycle loading and the low stress-high cycle loading of the three materials in Table 9. The data of table 9 indicates that the fatigue life is over predicted by 15 percent for the $2 \mathrm{v} / \mathrm{o}$ volume fraction untreated carbon fiber reinforced cement and that the error for the $1 \mathrm{v} / \mathrm{o}$ treated carbon fiber reinforced cement is about 38 percent. The error with the $1 \mathrm{v} / \mathrm{o}$ treated carbon fiber reinforced specimen was large partly because the mean life of the material at $25 \mathrm{MPa}$ was substantially greater than the other material types. Whereas the 2 v/o carbon fiber did not provide any reinforcement at the high stress-low cycle loading region of the S-N plots. 
Table 8: Area measurement of the high stress-low cycle specimens

\begin{tabular}{|c|c|c|c|c|c|c|}
\hline Material Type & $\begin{array}{c}\text { Maximum } \\
\text { stress }\end{array}$ & $\begin{array}{c}\text { Fatigue } \\
\text { area } \\
{\left[\mathrm{mm}^{2}\right]}\end{array}$ & $\begin{array}{c}\text { Fracture } \\
\text { area } \\
{\left[\mathrm{mm}^{2}\right]}\end{array}$ & $\begin{array}{c}\text { Maximum } \\
\text { stress }\end{array}$ & $\begin{array}{c}\text { Fatigue } \\
\text { area } \\
{\left[\mathrm{mm}^{2}\right]}\end{array}$ & $\begin{array}{c}\text { Fracture } \\
\text { area } \\
{\left[\mathrm{mm}^{2}\right]}\end{array}$ \\
\hline Neat & $25 \mathrm{MPa}$ & 3.6 & 28.1 & $12 \mathrm{Mpa}$ & 15.2 & 16.5 \\
\hline 1 v/o PET & $25 \mathrm{MPa}$ & 5.1 & 26.6 & $12 \mathrm{Mpa}$ & 12.8 & 18.9 \\
\hline $\begin{array}{c}\text { 1v/o treated } \\
\text { carbon }\end{array}$ & $25 \mathrm{MPa}$ & 6.1 & 25.6 & $14 \mathrm{Mpa}$ & 13.0 & 18.7 \\
\hline $\begin{array}{c}2 \text { v/o as received } \\
\text { carbon }\end{array}$ & $25 \mathrm{MPa}$ & 5.3 & 26.4 & $14 \mathrm{Mpa}$ & 11.8 & 19.9 \\
\hline
\end{tabular}

Further comparisons at stress levels of 12 and $14 \mathrm{MPa}$ indicate that the fatigue life of the one percent volume fraction treated carbon fiber reinforced cements at the low stress (high cycle) region was over predicted by more than 15 percent while for the two percent volume fraction as received carbon reinforced composite cement and the one volume fraction PET composite cement were both underpredicted by 14 percent and over 7 percent respectively. This approach eliminated the dependence of the fatigue life prediction on the crack length, but required that the area of fatigue be determined in each case. Hence, this approach can only be used for materials where the fatigue life of a reference material is known, and where the fatigue areas can be determined. Since the fatigue and fast fracture regions were difficult to distinguish, SEM micrographs were required to demarcate these areas. Furthermore, it is a comparitive model and can not be used for novel materials for which little experimental fatigue data exists. Finally this approach has the short coming that it provides no information about how the fatigue life of a composite cement is related to: fiber loading, fiber properties, fiber length and fiber-matrix bonding.

Table 9: Comparison of the predicted life to the measured mean life of the fiber reinforced composite bone cements at high stress- low cycle loading of $25 \mathrm{MPa}$ and low stress-high cycle condition of 12 \& $14 \mathrm{MPa}$

\begin{tabular}{|c|c|c|c|c|}
\hline Material type & $\begin{array}{c}\text { Stress } \\
{[\mathrm{MPa}]}\end{array}$ & $\begin{array}{c}\text { Predicted life } \\
{[\text { cycles] }}\end{array}$ & $\begin{array}{c}\text { Mean life } \\
\text { [cycles] }\end{array}$ & $\begin{array}{c}\text { Error } \\
{[\%]}\end{array}$ \\
\hline 1v/o PET composite cement & \multirow{2}{*}{25} & 6201 & 7927 & 15 \\
\cline { 4 - 5 } & & 8836 & 14,217 & 38 \\
\cline { 4 - 6 } 1v/o treated carbon composite cement & & 9490 & 9137 & 4 \\
\hline 2v/o as received carbon composite cement & 12 & 825,457 & 889,961 & 7.3 \\
\hline 1v/o PET composite cement & 14 & 923,413 & 799,661 & 15.5 \\
\hline 1v/o treated carbon composite cement & 14 & 879,093 & $1,021,760$ & 14 \\
\hline 2v/o as received carbon composite cement & 14 & & 14 \\
\hline
\end{tabular}

In an attempt to quantify the influence of these fiber properties on fatigue life, the developments of presented ealier were also used to relate the the work of fracture to the work of fatigue. The work associated with fatigue damage in bone cement is given by Equation 25 where $\left(\frac{P_{\max }}{A-A_{F}}\right)$ is the fracture stress. The work of fracture can be replaced by the analytically derived work of fracture given by equation 9 and substituting the values of the work for interface creation, frictional debond and fiber pullout, then Equation 9 can be written as

$$
W_{F}=W_{N}+\frac{V_{f} \sigma_{f, u} L}{12}+\frac{\sigma_{f, u} V_{f} L}{100}+\frac{V_{f} L Y_{i f}}{r}
$$

To circumvent the necessity of measuring areas and the restriction of relying on available fatigue data, the fracture stress was assumed to be equal to the ultimate tensile stress. Making these substitutions for work of fracture in terms of the maximum value of the interface creation, frictional debond and the pullout work, the fracture stress, the equation for the plastic work of fatigue for composite bone cement, $\mathrm{W}_{\mathrm{Pc}}$, can be written as

$$
W_{P c}=\left[\frac{\sigma_{a}}{\sigma_{U T S C}}\right]^{-4}\left[W_{N}+\frac{V_{f} \sigma_{f, u} L}{12}+\frac{\sigma_{f, u} V_{f} L}{100}+\frac{V_{f} L Y_{i f}}{r}\right]
$$

Evaluating the plastic work of the composite cement and substituting in Equation 26 the number of cycles to failure of the composite cement can be written in the following form

$$
N_{C}=N_{N}\left[\frac{\sigma_{\text {UTSC }}}{\sigma_{\text {UTSN }}}\right]^{4}\left[W_{N}+\left(\frac{V_{f} \sigma_{f, u} L}{12}\right)+\left(\frac{\sigma_{f, u} V_{f} L}{100}\right)+\left(\frac{V_{f} L Y_{i f}}{r}\right)\right]
$$


This equation can be used to predict life without extensive area measurements. The results obtained using this approach are compared with the experimental data in Tables 10 for the same materials at the $25 \mathrm{MPa}$ and $15 \mathrm{MPa}$ stress levels.

The results in Table 10 show that the fatigue life of the one percent by volume carbon and PET fiber reinforced cements were substantially over predicted. Further, the error between the predicted and the measured fatigue life for the two percent by volume carbon fiber reinforced bone cement was over $30 \%$, but the error is conservative for the comparions at $25 \mathrm{MPa}$. While the errors associated with these techniques are large, it must be kept in mind that the error in calculating the fracture energy dissipation terms had errors of about 10 to $20 \%$ associated with them. Hence it is to be expected that the errors in the fatigue prediction would be larger. Similar to the previous prediction, this model is comparative, but it does have the advantage of not being dependent on the area of fatigue as an input variable. Further the work of fracture does not consider the effect of crack meandering in fatigue, the bifurcation of the cracks, nor the possibilty of microcrazing in the brittle material also fatigue cracks initiate at regions of high surface porosity. The effect of these pores and the resulting stress concentration in the vicinity of these pores have not been addressed during the present investigation. Fiber clumping was accounted for by reducing the effective fiber volume factor, but the fiber clumps were not considered as stress concentration sites in this investigation.

Table 10: Comparison of the predicted \& experimentally determined fatigue lives of fiber reinforced composite bone cements

\begin{tabular}{|c|c|c|c|c|}
\hline Material type & $\begin{array}{c}\text { Maximum stress } \\
{[\mathrm{MPa}]}\end{array}$ & $\begin{array}{c}\text { Predicted life } \\
\text { [cycles] }\end{array}$ & $\begin{array}{c}\text { Mean life } \\
\text { [cycles] }\end{array}$ & $\begin{array}{c}\text { Error } \\
{[\%]}\end{array}$ \\
\hline 1v/o PET composite cement & 15 & 352,500 & 293,528 & 20 \\
\hline $\begin{array}{c}\text { 1v/o as received carbon composite } \\
\text { cement }\end{array}$ & 15 & 465,200 & 428,604 & 32 \\
\hline $\begin{array}{c}\text { 2v/o as received carbon composite } \\
\text { cement }\end{array}$ & 15 & 408,100 & 717,072 & 37 \\
\hline 1v/o PET composite cement & 25 & 4989 & 7927 & 28 \\
\hline $\begin{array}{c}\text { 1v/o as received carbon composite } \\
\text { cement }\end{array}$ & 25 & 6624 & 9137 & 19 \\
\hline 2v/o as received carbon composite \\
cement
\end{tabular}

Fractographic Analysis

Fractography is the descriptive analysis of the topographic features of fracture surfaces for the purpose of identifying the paths followed by the cracks as they propagate through the material during the fracture process. Understanding the influence of added fibers on the fracture mode is central to any investigation of how composite reinforcement may serve to improve fatigue resistance. The fracture surfaces of the representative specimens were sputter coated with a thin film of silver. SEM micrographs of the fracture surfaces were made using a Philips 515 Scanning Electron Microscope, where the accelerating voltage was in the range of 12 to $15 \mathrm{KV}$. The specimens of neat and composite cement were divided into several categories namely:

- tensile test specimens

- fatigue specimens at high stress(low cycle)

- fatigue specimens at low stress(high cycle).

\section{Tensile test specimens}

Fractured surfaces of all the materials were viewed under the scanning electron microscope and the detailed results of these observations can be referred to in [13]. In this article only the neat bone cement and the 2 v/o carbon fiber reinforced bone cement are presented.

\section{Neat bone cement}

The fracture surface of all the tensile test specimens exhibited microbrittle characteristics i.e., appeared brittle at the microscopic level, in that no zone of microductility could be observed in any of the specimen types. The cracks seem to have originated from the zones where surface porosity was high as shown in Fig.7 and to have propagated rapidly thereby preventing the region around the crack initiation site from experiencing any plastic deformation as shown in Fig.8. The prepolymerized bone cement beads are smooth and featureless as shown in Fig. 8, here it can also be noted that the crack propagated through the prepolymerized beads as well as the matrix, and the surface is rough with an irregular topography and was characterized by the overall pattern of chips or flake like features called hackles [25]. 

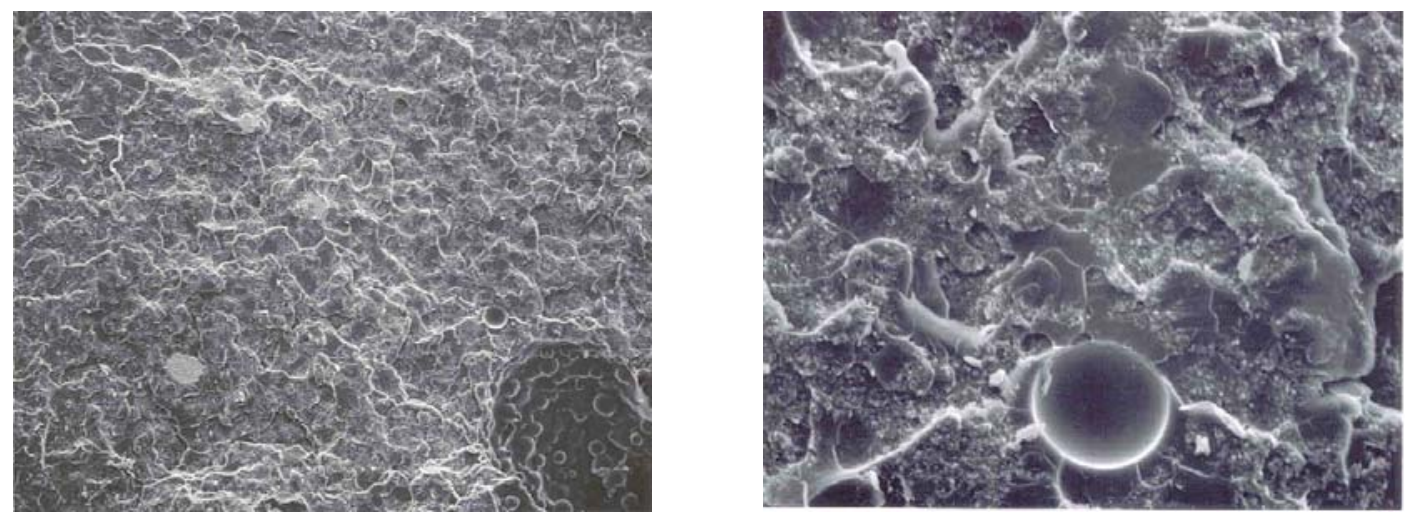

Figure 7: Tensile test specimen neat cement region around a pore probable location of the initiation of the fracture, magnification of 100X and Figure 8: Tensile test specimen neat cement, fracture path going through the beads of PMMA magnification 2200X.

\section{Two percent by volume carbon fiber reinforced cement}

The two percent by volume carbon fiber reinforced tensile specimen fracture surface is shown in figures 9 and 10 . Figure 9 shows a zone where the fibers pulled out of the cement and the surface features of the fibers are reproduced in the cement envelope. Figure 10 shows a fiber on the fracture surface, which is still embedded in the matrix. This is another indication that bonding between the carbon fiber and the bone cement matrix was strong. Overall no indication of localized plasticity was found in any fractograph and it was concluded that the fractures were entirely brittle.
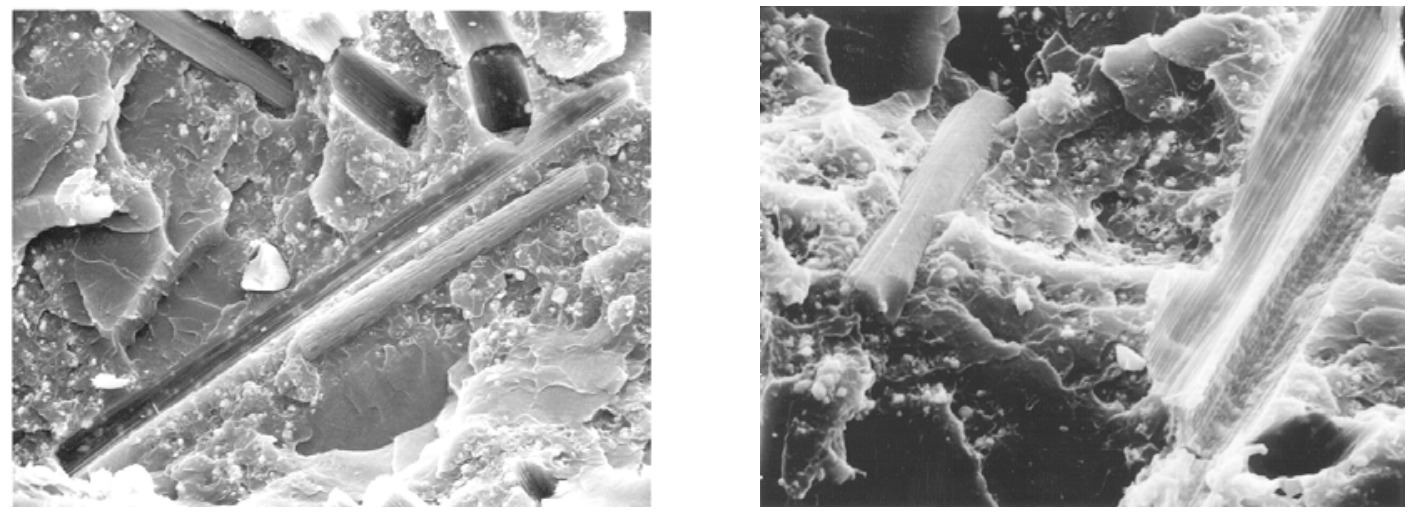

Figure 9: Tensile test specimen of 2v/o carbon fiber reinforced, shows carbon fiber in the region of brittle fracture, magnification 1250X and Figure 10: Carbon fiber bonded to cement on the fracture surface magnification 1666X

\section{High stress-low cycle fatigue}

The specimens exposed to the high stress (low cycle) fatigue were all tested at a maximum stress of $25 \mathrm{MPa}$. The specimen types examined were:

- Neat bone cement

- one percent by volume scoured PET reinforced bone cement

- two percent by volume as received carbon fiber reinforced bone cement

\section{Neat bone cement}

The specimen observed was a neat bone cement fatigue specimen, which failed after 5,058. cycles at a maximum stress of 25 $\mathrm{MPa}$. Two distinctly different fractographic zones are clearly recognizable in figure 11 showing he whole specimen. The first is a semicircular region, which is symmetrical about the large subsurface voids at the left. This region is relatively smooth and includes several ratchet marks. It appears that the fatigue cracks grow from different initiation sites not necessarily on the same plane, but merged to form steps or ridges called ratchet marks shown in Fig 12. The second fractographic zone, to the right of the fatigue region was rougher with a more irregular topography and was characterized by the overall pattern of chips or flake like features called hackles shown in Fig.13. Hackle formation is typical of single cycle tensile failure in bone cement 
and this zone is therefore identified as the region of abrupt tensile failure produced when the load bearing cross section was so reduced by the growth of the fatigue
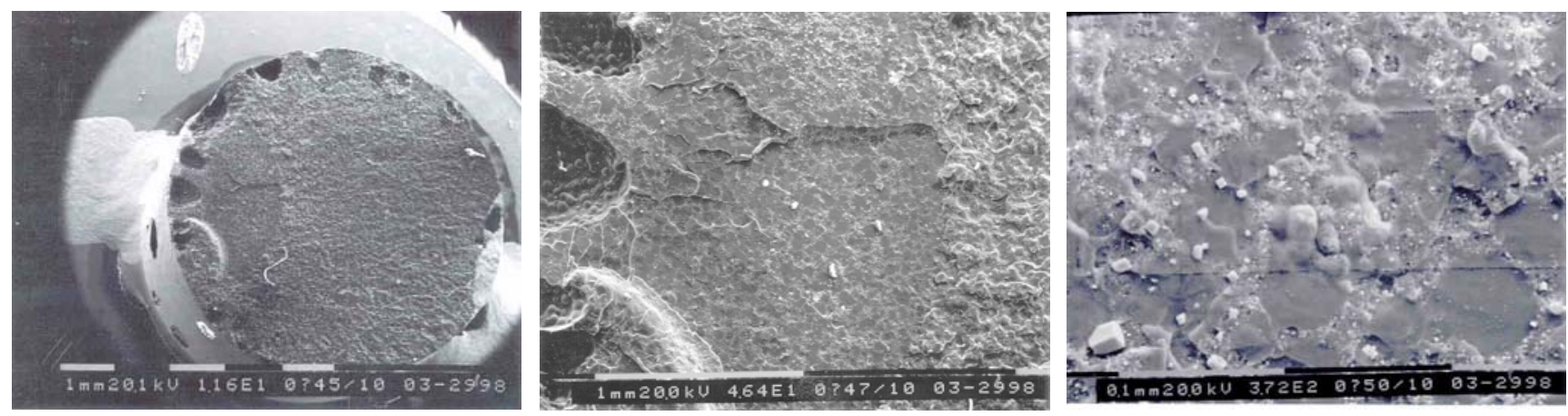

Figure 11, 12 and 13: Neat cement tested at $25 \mathrm{MPa}$ failed after 5058 cycles, magnification 11.6X, the crack initiation sites seen in figure 12 and fatigue region shown in figure 13.

\section{PET fiber reinforced cement}

The scoured PET fiber reinforced fatigue specimen is shown in Fig.14 fractured after surviving 11,408 cycles of loading at a maximum stress of $25 \mathrm{MPa}$. As with the tensile specimens the tilted image shown in Fig. 14 reveals the unevenness of the fracture surface. Pores at the specimen surface are also evident. Fig. 15 shows the transition from the fatigue region to the region of abrupt tensile fracture as well as the abundance of fibers (approximately 70 fibers $/ \mathrm{mm}^{2}$ ) traversing the fracture surface. Figure 16 is a photomicrograph at a magnification of $772 \mathrm{X}$ of the abrupt fracture region. The debonded fibers show absolutely no matrix particles adhering to them, suggesting that the fibers were debonded before they pulled out of the matrix or they were never bonded at all. Further there are no markings in the cement in the region where fiber pull out occurred during fracture.
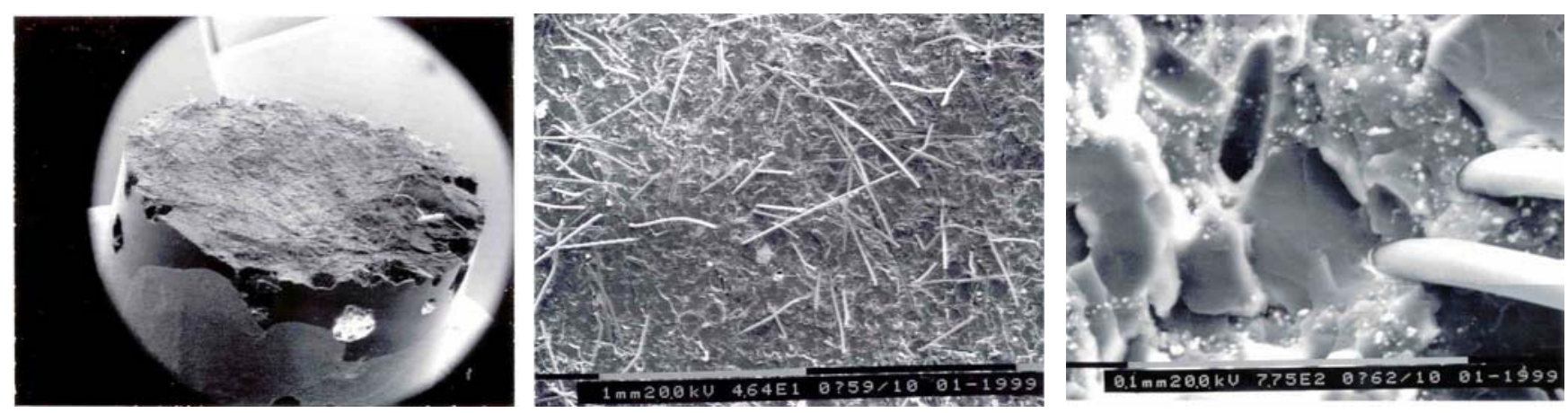

Fig 14, 15 \& 16: Scoured PET 1 v/o reinforced specimen tested at $25 \mathrm{MPa}$ and fractured after 11,408 cycles magnification, Fatigue-abrupt fracture transition region, and the Abrupt fracture region failure in the last loading cycle.

\section{Two percent by volume as received carbon fiber reinforced cement}

The bone cement specimen reinforced with two percent by volume as received carbon fibers failed after 13,388 cycles of loading at a maximum stress of $25 \mathrm{MPa}$. The surface features revealed in Figure 7 are such that the fatigue and the abrupt fracture regions are difficult to distinguish and the specimen is marked by the presence of pores. Figure 18 is a photomicrograph from the abrupt fracture region. The white particles are radiopacifier $\left(\mathrm{BaSO}_{4}\right)$ particles in the cement. Due to the increased volume of fibers, the fibers are in closer physical proximity to each other introducing an increased clumping tendency 

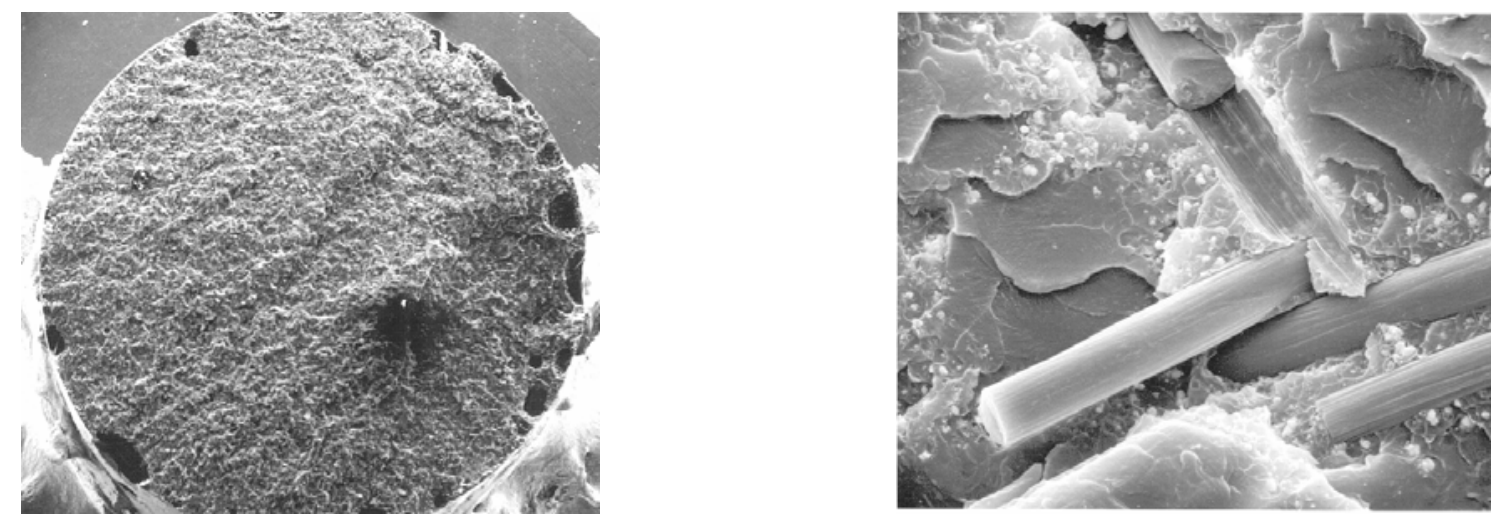

Figure 17: 2v/o as received carbon fiber reinforced specimen failed after 13,388 cycles at $25 \mathrm{MPa}$ and Figure 18; The Abrupt fracture region with higher density and clumping of fibers magnification.

\section{Low stress-high cycle fatigue}

Specimens exposed to stresses in the range of 12 to $14 \mathrm{MPa}$ survived between 700,000 to 800,000 cycles before fracturing. The neat and PET reinforced bone cement specimens were tested at a maximum stress of $12 \mathrm{MPa}$ while the carbon reinforced bone cement specimens were tested at a slightly higher maximum stress of $14 \mathrm{MPa}$. The reason for this was the endurance limit of the carbon fiber reinforced cement was above $13 \mathrm{MPa}$ and hence they could not be tested to failure in less than $10^{6}$ cycles at $12 \mathrm{MPa}$.

\section{Neat bone cement}

The neat cement specimen tested at a maximum stress of $12 \mathrm{MPa}$ survived for 715,446 cycles before failing. At low magnifications there was no clear distinction between the microtopography of the fatigue and abrupt fracture zones as shown in Figure 19. This was in marked contrast to the other neat bone cement specimens which were tested at higher stress levels. Figure 20 shows the outlines of the prepolymerised PMMA beads indicating that the region fractured in fatigue. As expected the fatigue zone was much larger than it was in the high stress fatigue specimens and the fatigue cracks originated at multiple sites, which joined together resulting in failure of the specimen.

\section{PET reinforced cement}

The one percent by volume PET fiber reinforced specimen tested at a maximum stress of $12 \mathrm{MPa}$ survived for 795,583 cycles of loading. Figure 21 shows the presence of subsurface and surface pores from which the fatigue cracks most likely originated The abrupt fracture zone shown in Figure 22 is marked by the fractured beads of PMMA marked by the presence hackles.

\section{Two percent by volume treated carbon fiber reinforced cement}

The bone cement specimen reinforced with two percent by volume as received carbon fiber tested at a maximum stress of 14 MPa failed after 706,292 cycles. This specimen surface has regions of fatigue with a ratchet step in the middle as shown in Figures 23 and 24. Figure 24 shows matrix adhered to a fiber after fracture, which is evidence of bonding between the carbon fiber and the bone cement.
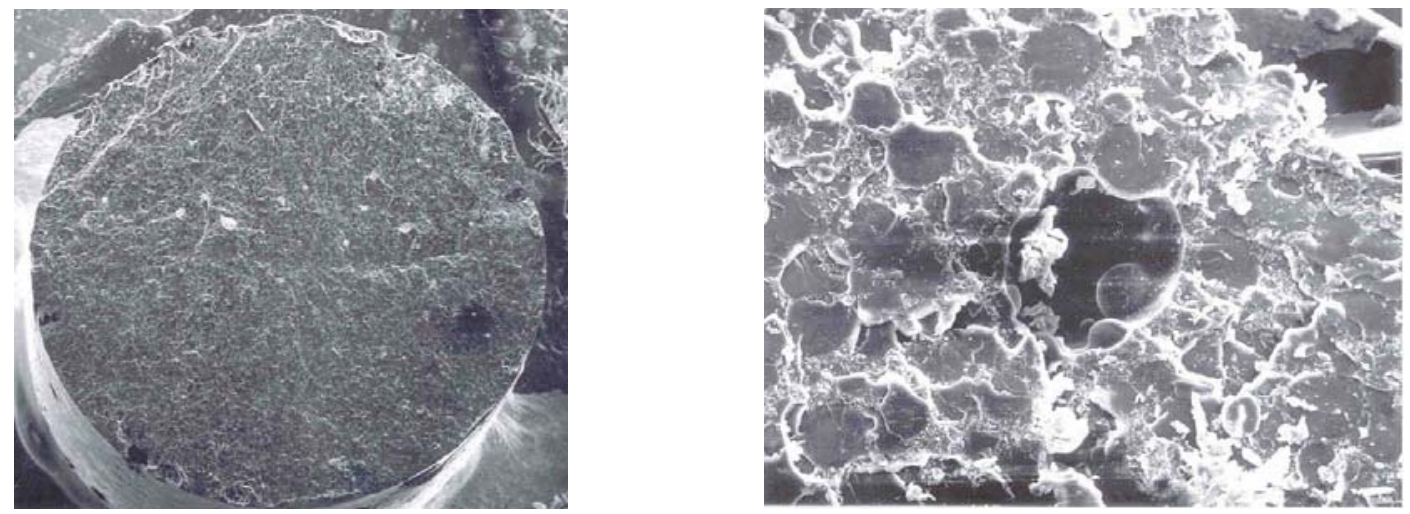

Figures 19: Neat bone cement specimen tested at $12 \mathrm{MPa}$ failed after 715,446 cycles magnification and Figure 20: The Fatigue region showing the presence of fractured PMMA beads approximate magnification 240X 

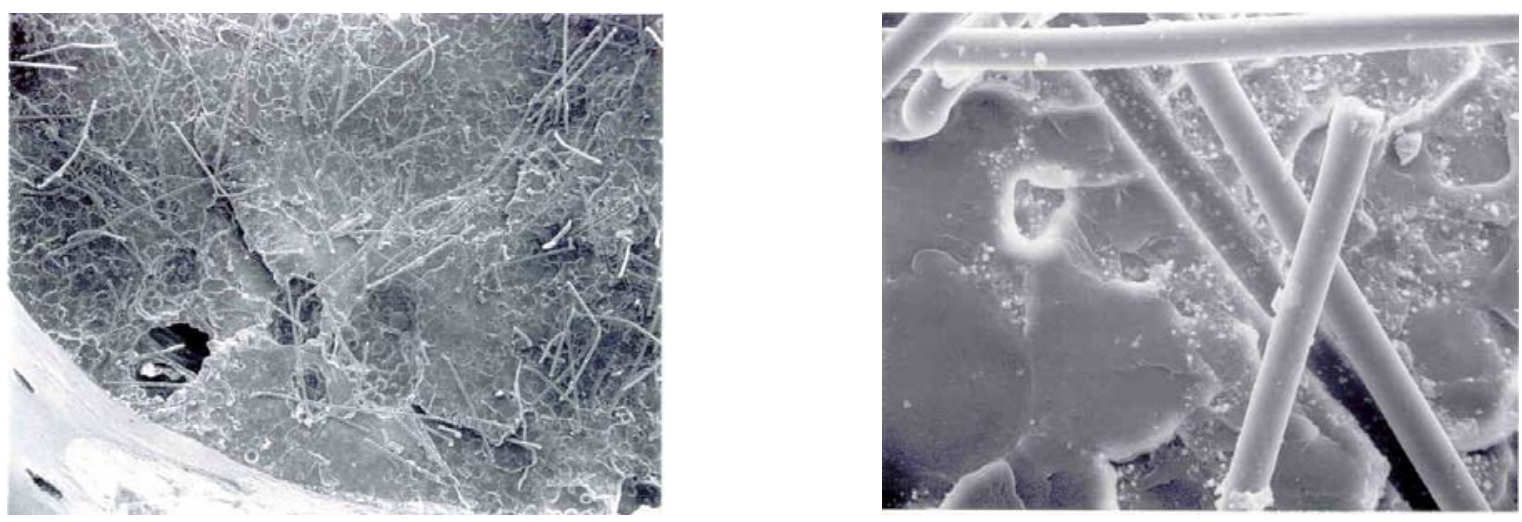

Figures 21: 1v/o PET fiber reinforced specimen tested at a maximum stress of $12 \mathrm{MPa}$ failed after 796,583 cycles and Figure 22: The Abrupt fracture region of PET reinforced specimen marked by the presence of hackles.
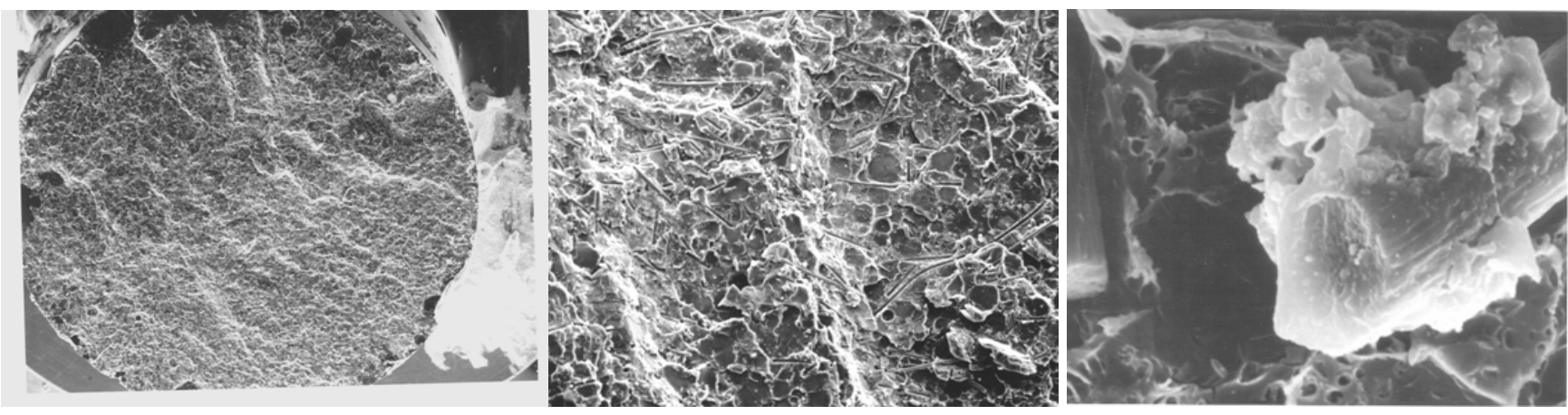

Fig 23: 2 v/o As received carbon fiber reinforced bone cement tested at a maximum stress of 14 MPa failed after 706,292 cycles, Figure 24: Ratchet marks in the fatigue fracture region of the specimen and Figure 25: Matrix adhered to the carbon fiber

\section{Conclusions}

The fracture of the bone cement mantle in total joint arthoplasty has been a concern ever since it was first used in surgery. The fractures have been attributed primarily to the poor fatigue resistance of the cement material. The objective of this research was to evaluate means for enhancing the fatigue resistance of the bone cement by the addition of short fibers. Two types of fibers, flexible PET fibers and milled stiff carbon fibers were selected as possible reinforcement additives. The effect of the different fiber lengths, fiber surface treatments, specimen preparation techniques and different fiber volume fractions were investigated to determine which parameters had the greatest impact on the reinforcing effect. An accurate measurement of the fatigue properties of a material depends upon the methodology of testing, especially the mode of testing, the range of loading, frequency of loading and the test environment. For this investigation the specimen fabrication and testing procedures were strictly monitored to insure against any additional factors influencing the results of the fatigue tests. The results showed the greatest effect on the fatigue life was in increasing the volume fraction of the carbon reinforced cement. The effect of the fiber length on the fatigue properties of PET reinforced cement was marginal, as was the effect of surface treatment of the fibers. The effect of the fiber modulus on the fatigue life of bone cement was substantial, with the carbon fiber reinforcements being stronger then the PET fiber reinforcement.

Certain classical structural analytical treatments of composites were adapted to generate a comparative model, which required experimental inputs. The terms for the energy dissipation processes were arrived at by making assumptions, which were not strictly in keeping with the observed behavior. The analytical terms for the fracture of the fiber reinforced composite bone cement predicted that the effect of the fiber length to be substantial in increasing fracture toughness. However, this was not found to be true with the actual measured data. The effect of the fiber volume fraction on the analytical prediction of life, was not in keeping with the experimental observations. An increase in fiber volume increased the energy required for fracture, but not to the magnitude observed experimentally. The analytical model had the shortcoming of not being able to account for the different behaviors seen at the two ends of the loading spectrum and this led to errors in predicting the fatigue life. The effect of fiber stiffness on the analytical life prediction was two fold; the influence of frictional debonds decreased with the increase in 
stiffness, but the stresses that arise in the fibers were directly proportional to the stiffness of the fibers. This is a probable explanation why the carbon fiber was a much better reinforcement.

PMMA based bone cement contains additives and the curing process produces increased surface porosity that can be reduced, but not eliminated. Consequently, the material contains numerous inherent flaws, any one of which can act as a dominant crack initiator. The fractographic analysis indicated that there could be more than one dominant fatigue crack that propagates through the material. The fatigue crack propagated across the beads of PMMA with no preference for an interparticle path. The carbon fibers seemed to form a stronger bond with the bone cement as was evidenced by the features of the fiber surface reproduced on the cement. Furthermore, the cement envelope around the carbon fiber had fractographic features that were not present on the PET reinforced cement. The carbon fibers in the region fractured by fatigue were completely debonded. It is conjectured that the bond between the carbon fibers and the bone cement was due to longitudinal striations in these fibers, which may have created more surface to which the cement could adhere resulting in stronger reinforcement. The fracture surface was marked by the presence of hackles and ratchet marks. There was no evidence of fatigue striations forming on any of the fracture surface. All the fatigue cracks originated from the surface in the vicinity of the pores present in this location. The presence of pores and the role they play in initiating cracks was evident from the photomicrographs, but to quantify these effects in analytical terms was difficult.

From the overall observation of the fatigue test data, the statistical analyses, analytical model and the fractographic analysis, it can be concluded that the reinforcement of the bone cement with the stiffer carbon fibers was moderately beneficial to its fatigue life. Experimental results indicated that the fiber volume fraction had the strongest influence on fatigue life at the low stress region and a possible weakening effect at the higher stress region. This could indicate a limit for the volume of fibers that should be incorporated into the bone cement. Since the fiber lengths that can be used effectively are small, fiber fracture is unlikely to occur and only fiber pullout is observed in these composites. Hence, increased fiber volume using stiff fibers and a stronger fiber matrix interface should result in the stronger reinforcement of bone cement.

\section{Acknowledgments}

This research was sponsored by VVARD. We are grateful to the late Dr. W. Winters for his encouragement and cooperation. The authors also are extremely grateful to the staff of Orthopaedic Research Institute, Inc., Via-Christi Health Systems at St. Francis Campus in Wichita KS USA.

\section{References}

1. Carter, D. R., Gates, E. I. and Harris, W. H., "Strain Controlled Fatigue of Acrylic Bone Cement," Journal of Biomedical Materials Research, 16, 647-657(1982).

2. Davies, J. P., O'Connor, D. O., Burke, D. W., Jasty, J. and Harris W. H., "The Effect of Centrifugation on the Fatigue Life of Bone Cement in the Presence Surface Irregularities," Clinical Orthopaedic and Related Research, Vol. 229, 156161(1988).

3. Fritag, T. A., and Cannon, S. L., "Fracture Characteristics of Acrylic Bone Cements II," Journal of Biomedical Materials Research, 13, 339-342(1979).

4. Fritch, W.E., "Static and Fatigue Properties of Two New Low-Viscosity PMMA Bone Cements Improved by Vacuum Mixing," Journal of Biomedical Materials Research, 13, 451-456(1996).

5. Gates, E. I., Carter, D. R. and Harris, W. H., "Tensile Fatigue Failure of Acrylic Bone Cement," Transactions of the ASME: Journal of Biomechanical Engineering, 105, 393-397(1983).

6. Harrigan, T. P., Davies, J. P., Burke, D. W., O'Connor, D. O., and Harris, W.H., "On the Presence or Easy Initiation of Fracture in Bone Cement Interface in Total Joint Arthoplasty," Transactions of the $13^{\text {th }}$ Society of Biomaterials (1987).

7. Krause, W., and Mathis, R. S.," Fatigue Properties of Bone Cements: Review of the Literature," Journal of Biomedical Materials Research, 22, No. A1, 37-53(1988).

8. Johnson, J. A., Provan, J.W., Krygier, J. J., Chan, K. H. and Miller, J., "Fatigue of Acrylic Bone Cement - Effect of Frequency and Environment," Journal of Biomedical Materials Research, 23, 819-831(1989).

9. Pilliar, R. M., Blackwell, R., Macnab, I., and Cameron, H. U., "Carbon Fiber Reinforced Bone Cement in Orthopaedic Surgery," Journal of Biomedical Materials Research, 10, 893-906(1976).

10. Topoleski, L. D. T., Ducheyne, P. and Cuckler, J. M., "Fracture Toughness of Titanium Fiber Reinforced Bone Cement," Journal of Biomedical Materials Research, 26, 1599-1617, 1992.

11. Topoleski, L. D. T., Ducheyne, P. and Cuckler, J. M., "Mechanism of the Fatigue Crack Propagation in Acrylic Bone Cement," Transactions $16^{\text {th }}$ Annual Meeting of the Society for Biomaterials(1990).

12. Topoleski, L. D. T., Ducheyne, P. and Cuckler, J. M., "A Fractographic Analysis of In Vivo Poly(methyl methacrylate) Bone Cement Failure Mechanisms," Journal of Biomedical Materials Research, 24, 135-154(1990).

13. Kumar B., "The Fatigue Behavior of an Amorphous Brittle Composite Material," PhD. Dissertation (2000).

14. Krause, W., and Mathis, R. S.," Fatigue Properties of Bone Cements: Review of the Literature," Journal of Biomedical Materials Research, 22, No. A1, 37-53(1988).

15. Little, R. E., Manual on Statistical Planning and Analysis, ASTM STP 588 (1975).

16. Mandell, J. F., "Fatigue Behaviour of Short Fiber Composite Materials," Fatigue of Composite Materials, Chapter 7 edited K. L. Reifsnider, Elsevier Science Publishers B. V. (1990). 
17. Marshall, D. B., Cox, B. N. and Evans, A. G., "The Mechanics of Matrix Cracking in Brittle Matrix Fiber Composites," Acta Metallurgica, $2013-2021$ (1985).

18. Kelly. A., Strong Solids, 2nd edition Oxford University Press (1973).

19. Horst, J.J., "Influence of Fibre Orientation on Fatigue of Short Glass Fibre Reinforced Polyamide," PhD Dissertation, Technishe Univeritiet Delft (1997).

20. Karam, G. N., "Effect of Fiber - Fiber Interaction on the Strength Properties of Short Fiber Reinforced Cements," Journal of Composites Technology \& Research, 16 No. 2, 154-160 (1994).

21. Jayatilaka, A. De. S., Fracture of Engineering Brittle Materials, Applied Science Publishers (1979).

22. Marston, T. U., Atkins, A. G., and Felbeck, D. K., "Interfacial Fracture Energy and the Toughness of Composites," Journal of Material Science, 9, 447-455 (1974).

23. Friis, E. A., Kumar, B., Cooke, F. W. and Yasuda, H. K., "Fracture Toughness of Surface Treated PET Fiber Composite Bone Cement," Transactions of the $\mathbf{2 2}^{\text {nd }}$ Society of Biomaterials (1996).

24. Friis, E. A., Kumar, B., Cooke, F. W. and Yasuda, H. K.," Fracture Toughness of Surface Treated Carbon Fiber Composite Bone Cement," Transactions of the $22^{\text {nd }}$ Society of Biomaterials (1996).

25. Kusy, R. P., "Characterization of Self-Curing Acrylic Bone Cements," Journal of Biomedical Materials Research, 12, 271305(1978). 